\title{
Síntese, atividade antifúngica e docking molecular de derivados do eugenol
}

Synthesis, antifungal activity and molecular docking of eugenol derivatives

\author{
J. A. C. Lima ${ }^{1}$; J. F. Silva ${ }^{1}$; R. R. A. Caiana ${ }^{2}$; J. P. Silva Júnior²; W. A. Oliveira²; \\ J. C. R. Freitas ${ }^{1,2 *}$ \\ ${ }^{1}$ Departamento de Química, Universidade Federal Rural do Pernambuco, 52171-900, Recife-PE \\ ${ }^{2}$ Centro de Educação e Saúde, Universidade Federal de Campina Grande, 58175-000, Cuité- PB
}

*julianocrufino@pq.cnpq.br

(Recebido em 27 de fevereiro de 2020; aceito em 29 de maio de 2020)

\begin{abstract}
Este trabalho descreve a síntese e atividade antifúngica de derivados do eugenol e o docking molecular do eugenol contendo uma unidade 1,2,3-triazólica. Os derivados de eugenol foram obtidos por modificações fenólicas na hidroxila, enquanto a concentração inibitória mínima foi determinada pelo método de microdiluição em caldo. O docking molecular do derivado de eugenol com funcionalidade 1,2,3-triazol foi realizado com a enzima esterol 14-alfa desmetilase (CYP51) e demonstrou que este composto não interage favoravelmente com esta enzima, diferentemente do posaconazol. Os derivados do eugenol foram obtidos com bons rendimentos e a avaliação antifúngica mostrou que, após modificações, a atividade antifúngica foi mantida em alguns exemplos. O resultado do docking molecular nos permitiu vislumbrar alguns motivos que justificam a ausência de atividade antifúngica do derivado de eugenol com funcionalidade 1,2,3-triazol. Em resumo, o artigo fornece informações importantes que ajudarão na realização de pesquisas futuras envolvendo este produto natural.

Palavras-chave: eugenol, atividade antifúngica, triazol.
\end{abstract}

This work describes the synthesis and antifungal activity of eugenol derivatives and the molecular docking of eugenol containing a 1,2,3-triazole unit. Eugenol derivatives were obtained by phenolic hydroxyl modifications, while the minimum inhibitory concentration was determined by the broth microdilution method. Molecular docking of the eugenol derivative bearing 1,2,3-triazole functionality was performed with the enzyme sterol 14-alpha demethylase (CYP51) and demonstrated that this compound did not interact favorably with this enzyme, unlike posaconazole. Eugenol derivatives were obtained in good yields and antifungal evaluation showed that, after modifications, antifungal activity was maintained in some examples. The result of molecular docking allowed us to glimpse some reasons that justify the absence of antifungal activity of the eugenol derivative bearing 1,2,3-triazole functionality. In short, the paper provides important information that will help in conducting future research involving this natural product.

Keywords: Eugenol, antifungal activity, triazole.

\section{INTRODUÇÃO}

As infecções fúngicas vêm preocupando os órgãos de saúde do mundo devido suas elevadas taxas de morbimortalidade nas últimas décadas [1]. Por exemplo, dados epidemiológicos indicam uma taxa de $40 \%$ de mortalidade em pacientes infectados por Candida spp. [2], sendo isto justificado devido essa levedura está presente na microbiota humana, podendo causar doenças em diferentes locais da anatomia humana e com diferentes graus de severidade [3, 4].

Dentre as espécies de Candida spp., a Candida albicans é a mais prevalente tanto em pacientes sadios quanto em indivíduos mórbidos [5], em que, apenas em 2015 acometeu entre 9,5 a 14,4 indivíduos para cada 100.000 habitantes norte-americanos [6].

Vale ressaltar que a literatura enfatiza a resistência de várias espécies de Candida spp. aos antifúngicos comerciais [4, 7-10], sendo isto um dos desafios para a medicina moderna [11], uma vez que limita as opções de tratamento [12]. Desta forma, o desenvolvimento de novos antifúngicos tem sido constantemente necessário no tratamento clínico das infecções fúngicas [13]. 
Neste tocante, os produtos naturais apresentam-se como uma boa alternativa no desenvolvimento de novos fármacos, uma vez que muitas moléculas oriundas de fonte naturais exibem interessantes atividades biológicas, a citar o eugenol, pertencente à classe dos fenilpropanóides, o qual atua como antibacteriano e antifúngico $[14,15]$. Além disso, o eugenol atua como analgésico, antioxidante, anti-inflamatório, antiespasmódico, antidepressivo e anticarcinogênico [16, 17]. Adicionalmente, o eugenol vem sendo amplamente utilizado no setor alimentício, cosmético $[18,19]$ e odontológico $[20,21]$.

Estas aplicações tornam o eugenol uma estrutura interessante para modificações estruturais a fim de produzir novas substâncias com propriedades terapêuticas que possam vir a ser úteis no desenvolvimento de novos fármacos [22]. Entretanto, a trajetória desde a descoberta de uma molécula promissora até a sua aplicação como produto farmacêutico é bastante longa e conta com alguns entraves, o que tem fomentado uma intensa busca por métodos alternativos que contornem estas dificuldades, destacando-se os métodos in silico [23, 24]. No geral, um método in silico bastante empregado para esta finalidade é o docking molecular [25], uma vez que permite conjecturar sobre as possíveis interações que podem ser estabelecidas entre o candidato a fármaco e a biomolécula em questão, possibilitando uma melhor compreensão de suas propriedades farmacodinâmicas e fornecendo informações úteis para a condução de modificações estruturais futuras [26, 27].

Vale ressaltar que diversos trabalhos avaliam as propriedades antifúngicas do eugenol e seus derivados [28, 29], apontando a enzima esterol 14 $\alpha$-desmetilase (CYP51) como um potencial alvo molecular para o desenvolvimento de suas atividades antimicrobianas frente cepas fúngicas de importância médica [30, 31].

Diante do exposto, o trabalho visou realizar a síntese e caracterização estrutural de derivados do eugenol, avaliar a atividade antifúngica desses compostos frente a diferentes espécies de Candida e realizar estudos de docking molecular para um melhor entendimento da interação do derivado triazólico do eugenol frente a enzima esterol 14 $\alpha$-desmetilase (CYP51).

\section{MATERIAL E MÉTODOS}

\subsection{Reagentes e equipamentos}

Os reagentes e os solventes utilizados foram obtidas na forma comercial da Merck e SigmaAldrich, o hexano e o acetato de etila foram purificados através da destilação em coluna de Vigreaux. As reações foram monitoradas através da cromatografia em camada delgada (CCD) utilizando placas de sílica-gel contendo indicador fluorescente F254. As placas de CCD foram visualizadas por meio da utilização uma lâmpada de ultravioleta (UV) de comprimentos de onda entre 254 e $365 \mathrm{~nm}$.

A etapa de purificação dos derivados do eugenol sintetizados foi realizada através da cromatografia líquida em coluna de vidro utilizando sílica-gel 60 Merck (70-230 mesh) como fase estacionária e como fase móvel os solventes hexano e acetato de etila em diferentes proporções de sistemas. As misturas reacionais foram evaporadas em um evaporador rotativo da Büchi Rotavapor modelo R-114 conectado a uma bomba de vácuo modelo KNF Neuberger.

$\mathrm{O}$ infravermelho (IV) foi realizado em um espectrofotômetro de infravermelho com transformada de Fourier Spectrum 400 FT-IR/FT-NIR Spectrometer modelo Perkin Elmer. O espectro IV de transmissão foram obtidos com resolução $4 \mathrm{~cm}^{-1}$, ganho 1, região espectral 4000 a $400 \mathrm{~cm}^{-1}$ e 40 varreduras. A amostra foi submetida à análise de IV preparada como pastilhas de $\mathrm{KBr}$. Os teores de carbono, hidrogênio e nitrogênio dos compostos foram determinados pela técnica Dynamic Flash Combustion, em um analisador elementar CHNS-O, CE Instruments, modelo EA 1110.

A caracterização das estruturas dos compostos foi realizada através da técnica de ressonância magnética nuclear de hidrogênio $\left(\mathrm{RMN}{ }^{1} \mathrm{H}\right)$ e carbono $\left(\mathrm{RMN}{ }^{13} \mathrm{C}\right)$ em um espectrômetro Varian Unity Plus, cuja frequência para o núcleo de hidrogênio foi 400 ou $300 \mathrm{MHz}$ e para o núcleo de carbono foi de 100 ou $75 \mathrm{MHz}$. As análises foram realizadas utilizando como solvente o $\mathrm{CDCl}_{3}$. Os deslocamentos químicos foram expressos em $\delta(\mathrm{ppm})$ e as constantes de acoplamentos $(J)$ em hertz $(\mathrm{Hz})$ em relação ao pico central do $\mathrm{CDCl}_{3}(7,27)$ para o espectro de $\mathrm{RMN}{ }^{1} \mathrm{H}$ e para o espectro 
de $\mathrm{RMN}{ }^{13} \mathrm{C}$ os deslocamentos foram obtidos em relação aos picos centrais do $\mathrm{CDCl}_{3}(77,0)$. $\mathrm{O}$ aparelho foi calibrado usando $\mathrm{Si}\left(\mathrm{CH}_{3}\right)_{4}(0,0 \mathrm{ppm})$ como referência externa no caso do $\mathrm{RMN}{ }^{1} \mathrm{H}$ e ${ }^{13} \mathrm{C}$.

\subsection{Procedimento Experimental para Síntese dos Derivados do Eugenol (2-6)}

Síntese 4-alil-2-metoxifenil acetato (2): Em um balão de fundo redondo adicionou-se o eugenol (164,2 mg; $1 \mathrm{mmol})$, acetato de sódio (184,6 mg; $2,25 \mathrm{mmol})$ e anidrido acético (1 mL; $10 \mathrm{mmol})$. A mistura reacional ficou sob agitação e temperatura ambiente por $8 \mathrm{~h}$. O término da reação foi comprovado por cromatografia de camada delgada (CCD) utilizando o sistema eluente hexano:acetato de etila, na proporção 90:10. Após a comprovação do término da reação, a mistura reacional foi transferida para um funil de separação, no qual foi adicionado $50 \mathrm{~mL}$ de solução salina e o produto extraído com acetato de etila $(3 \times 50 \mathrm{~mL})$. A fase orgânica foi separada e seca com sulfato de sódio anidro. Em seguida, a fase orgânica foi filtrada e o solvente removido sob pressão reduzida. $\mathrm{O}$ produto bruto foi purificado através de cromatografia líquida em coluna, utilizando sílica-gel 60 como fase estacionária e sistemas de hexano:acetato de etila (95:05, v:v) como fase móvel numa coluna de vidro segundo a metodologia descrita por Bem Arfa et al. (2006) [32].

Óleo incolor; $90 \%$ de rendimento; $185,6 \mathrm{mg}$; $\mathrm{RMN}^{1} \mathrm{H}\left(300 \mathrm{MHz}, \mathrm{CDCl}_{3}\right) \delta 6,94(\mathrm{~d}, \mathrm{~J}=7,5 \mathrm{~Hz}$, $1 \mathrm{H}), 6,73-6,78(\mathrm{~m}, 2 \mathrm{H}), 5,91-6,00(\mathrm{~m}, 1 \mathrm{H}), 5,05-5,15(\mathrm{~m}, 2 \mathrm{H}), 3,80(\mathrm{~s}, 3 \mathrm{H}), 3.37(\mathrm{~d}, \mathrm{~J}=6,6 \mathrm{~Hz}$, $2 \mathrm{H}), 2,29(\mathrm{~s}, 3 \mathrm{H}) ; \mathrm{RMN}^{13} \mathrm{C}\left(75 \mathrm{MHz}, \mathrm{CDCl}_{3}\right) \delta 169,1 ; 150,8 ; 138,94 ; 137,9 ; 136,9 ; 122,4 ; 120,6$; 116,$0 ; 112,6 ; 55,7 ; 40,0 ; 20,6$.

Síntese do 4-alil-1-(benziloxi)-2-metoxibenzeno (3): Em um balão de fundo redondo adicionouse 5,0 $\mathrm{mL}$ de acetonitrila, eugenol (164,2 $\mathrm{mg}, 1 \mathrm{mmol})$, carbonato de potássio anidro (414,6 $\mathrm{mg}, 3$ mmol) e brometo de benzila $(34,4 \mathrm{mg}, 0,2 \mathrm{mmol})$. A mistura reacional ficou sob agitação e refluxo por 4,3 h. O término da reação foi comprovado por cromatografia de camada delgada (CCD) utilizando o sistema eluente hexano: acetato de etila, na proporção 90:10. Após a comprovação do término da reação a mistura reacional foi transferida para um funil de separação, no qual foi adicionado $50 \mathrm{~mL}$ de solução salina e o produto extraído com acetato de etila $(3 \times 50 \mathrm{~mL})$. A fase orgânica foi separada e seca com sulfato de sódio anidro. Em seguida, a fase orgânica foi filtrada e o solvente removido sob pressão reduzida. O produto bruto foi purificado através de cromatografia líquida em coluna, utilizando sílica-gel 60 como fase estacionária e sistemas de hexano:acetato de etila (90:10, v:v) como fase móvel numa coluna de vidro conforme a metodologia descrita por Kumar et al. (2012) [33].

Óleo incolor, $92 \%$ de rendimento; $233,9 \mathrm{mg}$; $\mathrm{RMN}^{1} \mathrm{H}\left(300 \mathrm{MHz}, \mathrm{CDCl}_{3}\right) \delta 7,44-7,47(\mathrm{~m}, 2 \mathrm{H})$, 7,26-7,40 (m, 3H), 6,82 (d, J = 7,5 Hz, 1H), 6,75 (d, J = 2,4 Hz, 1H), 6,66 (d, J = 2,4 Hz, 1H), 5,906,04 (m, 1H), 5, 14 (s, 2H), 5,12-5,08 (m, 2H), 3,89 (s, 3H), 3,34 (d, J = 6,3 Hz, 2H). RMN ${ }^{13} \mathrm{C}(75$ $\left.\mathrm{MHz}, \mathrm{CDCl}_{3}\right) \delta 146,5 ; 137,5 ; 137,3 ; 133,2 ; 128,4 ; 127,6 ; 127,2 ; 120,3 ; 115,5 ; 114,2 ; 112,4 ; 71,1$; 55,$9 ; 39,7$.

Síntese do 4-alil-2-metoxi-1-(prop-2-in-1-iloxi)benzeno (4): Em um balão de fundo redondo adicionou-se o eugenol (164,2 mg, $1 \mathrm{mmol})$, o carbonato de potássio anidro (207,3 mg, 1,5 mmol) e $10 \mathrm{~mL}$ de acetona a temperatura ambiente. Em seguida foi adicionado lentamente o brometo de propargila ( $178 \mathrm{mg}, 1,5 \mathrm{mmol})$ e a mistura reacional ficou sob agitação e refluxo por $6 \mathrm{~h}$. O término da reação foi comprovado por cromatografia de camada delgada (CCD) utilizando o sistema eluente hexano:acetato de etila, na proporção 70:30. Após a comprovação do término da reação a mistura reacional foi transferida para um funil de separação, no qual foi adicionado $50 \mathrm{~mL}$ de solução salina e o produto extraído com acetato de etila $(3 \times 50 \mathrm{~mL})$. A fase orgânica foi separada e seca com sulfato de sódio anidro. Em seguida, a fase orgânica foi filtrada e o solvente removido sob pressão reduzida. O produto bruto foi purificado através de cromatografia líquida em coluna, utilizando sílica-gel 60 como fase estacionária e sistemas de hexano:acetato de etila (proporção 95:05) como fase móvel numa coluna de vidro conforme a metodologia descrita por He et al. (2012) [34].

Óleo amarelo, $88 \%$ de rendimento; $177,9 \mathrm{mg} ; \mathrm{RMN}^{1} \mathrm{H} ;\left(400 \mathrm{MHz}, \mathrm{CDCl}_{3}\right) \delta 6,97(\mathrm{~m}, 1 \mathrm{H}), 6,73-$ 6,71 (m, 2H), 5,9-6,0 (m, 1H), 5,12-5,06 (m, 2H), 4,73(d, J = 2,4 Hz, 2H), 3,86 (s, 3H), 3,34 (d, J 
$=6,8 \mathrm{~Hz}, 2 \mathrm{H}), 2,49(\mathrm{t}, \mathrm{J}=2,4 \mathrm{~Hz}, 1 \mathrm{H}) ; \mathrm{RMN}{ }^{13} \mathrm{C}\left(100 \mathrm{MHz}, \mathrm{CDCl}_{3}\right) \delta 149,5 ; 145,0 ; 137,4 ; 134,1$; 120,$2 ; 115,6 ; 114,6 ; 112,2 ; 78,7 ; 75,5 ; 56,8 ; 55,7 ; 39,7$.

Ácido 2-(4-alil-2-metoxifenoxi)acético (5): A obtenção do derivado 5 se deu em duas etapas. A primeira etapa formou o produto intermediário 3-(4-alil-2-metoxifenoxi)etanoato de etila e na segunda etapa obtemos o composto 5. Dessa forma, foi adicionado (1mmol) do 3-(4-alil-2metoxifenoxi)etanoato de etila a um balão de fundo redondo que foi solubilizado em $10 \mathrm{~mL}$ diclorometano/metanol (9:1, v/v), seguido da adição uma solução metanólica de $\mathrm{NaOH} 2 \mathrm{~N}$ (4 eq) e a mistura reacional ficou sob agitação e temperatura ambiente por $3 \mathrm{~h}$. após confirmado o termino da reação por meio da CCD. O solvente foi removido sob pressão reduzida, o resíduo foi diluído com água e adicionado ao funil de separação e o produto foi extraído com acetato de etila $(3 \times 50$ $\mathrm{mL}$ ). A camada aquosa foi então resfriada a $0^{\circ} \mathrm{C}$, acidificado a $\mathrm{pH}$ 2-3 com uma solução de $\mathrm{HCl}$ $2 \mathrm{~N}$, levando a um sólido branco que foi filtrado e seco segundo a metodologia descrita por Buckler et al. (2017) [35].

Sólido branco: P. F. $100,5^{\circ} \mathrm{C} ; 95 \%$ de rendimento; $211,1 \mathrm{mg} ; \mathrm{RMN}{ }^{1} \mathrm{H} ;\left(400 \mathrm{MHz}, \mathrm{CDCl}_{3}\right) \delta$ 6,85 (d, J= 8,4 Hz, 1H); 6,74-6,71 (m, 2H); 5,99-5,89 (m, 1H); 5,10-5,06 (m, 2H); 4,66 (s, 2H); $3,87(\mathrm{~s}, 3 \mathrm{H}) ; 3,34(\mathrm{~d}, \mathrm{~J}=6,8 \mathrm{~Hz}, 2 \mathrm{H}$ ) (o sinal do grupo ácido carboxílico não foi observado devido ao próton ácido). $\mathrm{RMN}{ }^{13} \mathrm{C}\left(100 \mathrm{MHz}, \mathrm{CDCl}_{3}\right) \delta 173,09 ; 149,62 ; 145,38 ; 137,16 ; 135,67 ; 120,82$; 116,$28 ; 115,95 ; 112,57 ; 67,70 ; 55,84 ; 39,81$.

Síntese do 3-(4-((4-alil-2-metoxifenoxi)metil)-1H-1,2,3-triazol-1-il)etanoato de etila (6): Em um balão de fundo redondo adicionou-se o composto 4 (202,2 $\mathrm{mg} ; 1,0 \mathrm{mmol})$, etil 2-azidoacetato (142 $\mathrm{mg} ; 1,1 \mathrm{mmol})$ e o ascorbato de sódio $(79,2 \mathrm{mg} ; 0,4 \mathrm{mmol}) 1,5 \mathrm{~mL}$ de etanol e $1,5 \mathrm{~mL}$ de água destilada. Por último foi adicionado o sulfato de cobre $\mathrm{I}\left(\mathrm{CuSO}_{4} .5 \mathrm{H}_{2} \mathrm{O}: 49,8 \mathrm{mg}, 0,202 \mathrm{mmol}\right)$. A mistura reacional ficou sob agitação a temperatura ambiente por $30 \mathrm{~min}$. O término da reação foi comprovado por cromatografia de camada delgada (CCD) utilizando o sistema eluente hexano:acetato de etila, na proporção 50:50. Após a comprovação do término da reação a mistura reacional foi transferida para um funil de separação, no qual foi adicionado $50 \mathrm{~mL}$ de solução salina e o produto extraído com acetato de etila $(3 \times 20 \mathrm{~mL})$. A fase orgânica foi separada e seca com sulfato de sódio anidro. Em seguida, a fase orgânica foi filtrada e o solvente removido sob pressão reduzida. $\mathrm{O}$ produto bruto foi purificado através de cromatografia líquida em coluna, utilizando sílica-gel 60 como fase estacionária e sistemas de hexano: acetato de etila (proporção 50:50) como fase móvel numa coluna de vidro conforme a metodologia descrita por Teixeira et al. (2017) [36].

Sólido branco: P.F. $93^{\circ} \mathrm{C}$; $80 \%$ de rendimento; $265,0 \mathrm{mg}$; IV (Pastilha de $\mathrm{KBr}$ ): $\lambda$ max 3138 , 3079, 2996, 1753, 1638, 1518, 1209, $1038 \mathrm{~cm}^{-1} ; \mathrm{RMN}^{1} \mathrm{H}\left(400 \mathrm{MHz}, \mathrm{CDCl}_{3}\right) \delta 7,75(\mathrm{~s}, 1 \mathrm{H}), 6,95$ $(\mathrm{d}, \mathrm{J}=7,6 \mathrm{~Hz}, 1 \mathrm{H}), 6,71-6,67(\mathrm{~m}, 2 \mathrm{H}), 5,88-5,98(\mathrm{~m}, 1 \mathrm{H}), 5,27(\mathrm{~s}, 2 \mathrm{H}), 5,11(\mathrm{~s}, 2 \mathrm{H}), 5,08-5,03(\mathrm{~m}$, $2 \mathrm{H}) ; 4,21-4,26$ (q, J = 7,3 Hz, 2H), 3,83 (s, 3H), 3,30 (d, J = 6,8 Hz, 2H), 1,28 (t, J = 7,3 Hz, 3H); $\mathrm{RMN}{ }^{13} \mathrm{C}\left(100 \mathrm{MHz}, \mathrm{CDCl}_{3}\right) \delta 166,0 ; 149,4 ; 145,8 ; 144,8 ; 137,4 ; 133,7 ; 124,2 ; 120,4 ; 115,6 ; 114,4$; 112,$2 ; 63,2 ; 62,3 ; 55,7 ; 50,8 ; 39,7 ; 13,9$. Anal. C, 61,73\%; H, 6,37 \%; N, 12,80\%. calcd for $\mathrm{C}_{17} \mathrm{H}_{21} \mathrm{~N}_{3} \mathrm{O}_{4}$ : C, 61,62\%; $\mathrm{H}, 6,39 \% ; \mathrm{N}, 12,68 \%$.

\subsection{Avaliação da Atividade Antifúngica}

A avaliação da atividade antifúngica foi realizada por meio de técnica da microdiluição em caldo [27] em que foi utilizado como meio o caldo Sabouraud dextrose. Foram utilizadas cepas de levedura padrão da American Type Culture Collection (ATCC) (Candida tropicalis ATCC-13803, Candida albicans ATCC-76615, Candida parapsilosis ATCC-22019 e Candida glabrata ATCC90030). A concentração inibitória mínima foi considerada a menor concentração capaz de inibir o crescimento visível do microrganismo [37]. O inóculo para cada um dos microrganismos foi preparado de acordo com o tubo 0,5 da escala de McFarland onde contém aproximadamente 1$5 \times 10^{6}$ UFC (unidades formadoras de colônia $/ \mathrm{mL}$ ). Os experimentos foram conduzidos com aproximadamente $1-5 \times 10^{5} \mathrm{UFC} / \mathrm{mL}$ em cada cavidade. As soluções do eugenol (1) e derivados (2-6) foram preparadas no momento da realização dos testes, em que se utilizou o dimetilsulfóxido (DMSO, na concentração inferior a 0,5\%) para solubilizar os compostos 1-6. Cada um dos compostos 1-6 foi testado nas concentrações $512-8 \mu \mathrm{g} / \mathrm{mL}$ em diluições seriadas 1:2. Inicialmente 
$100 \mu \mathrm{L}$ do meio de cultura foi adicionado em cada uma das cavidades de uma placa. Logo em seguida $100 \mu \mathrm{L}$ da solução dos compostos 1-6 (concentração final $512 \mu \mathrm{g} / \mathrm{mL}$ ) foi adicionado na primeira linha da placa e foi feita a diluição seriada 1:2 até a concentração $8 \mu \mathrm{g} / \mathrm{mL}$. Por último, 10 $\mu \mathrm{L}$ do inóculo foi adicionado em cada cavidade da placa. A placa foi incubada a $35^{\circ} \mathrm{C}$ por $24-48$ horas. Os experimentos foram realizados em triplicata e foram utilizados como controle positivo e negativo a anfotericina B e o solvente DMSO, respectivamente.

\subsection{Modelagem molecular}

Os estudos de docking molecular foram realizados utilizando o programa AutoDock 4.2.6. As estruturas tridimensionais do composto 6 e do posaconazol foram construídas usando o software Avogadro 1.2.0 [38] e totalmente otimizadas pelo método semi-empírico PM6 [39] implementado no MOPAC2016 [40]. Os ligantes no formato ".pdb" foram preparados para o docking fundindose os hidrogênios não polares com o carbono correspondente, calculando a carga parcial dos átomos usando o procedimento de Gasteiger e definindo as ligações rotáveis dos ligantes a partir do pacote AutoDockTools-1.5.6.

A enzima esterol 14 $\alpha$-desmetilase (CYP51) foi escolhida como alvo farmacológico para os estudos de docking molecular devido à sua relevância como alvo antifúngico de uma ampla gama de fármacos usados clinicamente. Sua estrutura cristalizada foi recuperada no RCSB Protein Data Bank com ID: 5FSA. O posaconazol foi escolhido como o fármaco de referência para estudos de docking molecular por se mostra como o inibidor mais potente da CYP51 [31]. Foi utilizado o algoritmo genético Lamarckiano no AutoDock 4.2.6 para a determinação das melhores conformações e orientações dos ligantes.

Através do grid box, foi definido o local de ancoragem na enzima CYP51 para os cálculos de docking molecular, utilizando-se como centro da caixa o ligante co-cristalizado desta enzima no RCSB Protein Data Bank, o posaconazol, com dimensão suficiente para alcançar os aminoácidos pertencentes ao sítio ativo [41]. As poses de acoplamento resultantes, bem como imagens mostrando interações enzima-ligantes, foram geradas e analisadas usando o AutoDockTools e o BIOVIA Discovery Studio Visualizer [42]. A validação dos parâmetros utilizados no docking molecular foi realizada através do estudo de re-docking realizado com o ligante co-cristalizado da enzima em questão, o posaconazol, sendo considerados efetivos os parâmetros capazes de reproduzir satisfatoriamente (expressar valores de Root Mean Standard Deviation - RMSD $\leq 2 \AA$ ) a conformação desse ligante constante no complexo obtido por cristalografia.

\section{RESULTADOS E DISCUSSÃO}

A estratégia geral para a síntese dos derivados do eugenol (2-6) está descrita na Figura 1, em que as mudanças estruturais aconteceram na hidroxila fenólica. Assim, o eugenol foi submetido às seguintes reações: Acetilação, $O$-Benzilação, $O$-Propagilação, Cicloadição, Alquilação seguida de hidrólise e Reação 1,3-dipolar catalisada por cobre.

O 4-alil-2-metoxifenil acetato (2), 4-alil-1-(benziloxi)-2-metoxibenzeno (3), 4-alil-2-metoxi-1(prop-2-in-1-iloxi)benzeno (4), ácido 2-(4-alil-2-metoxifenoxi)acético (5) e o 3-(4-((4-alil-2metoxifenoxi)metil)-1H-1,2,3-triazol-1-il)etanoato de etila (6) foram obtidos em rendimentos de 90, 92, 88, 95 e 80\%, respectivamente. Esses rendimentos são semelhantes aos valores descritos por Barbosa et al. (2012) [43], Hamri et al. (2009) [44], Teixeira et al. (2018) [36] e Buckler et al. (2017) [35]. No entanto, a literatura não descreve a síntese do composto 6. 


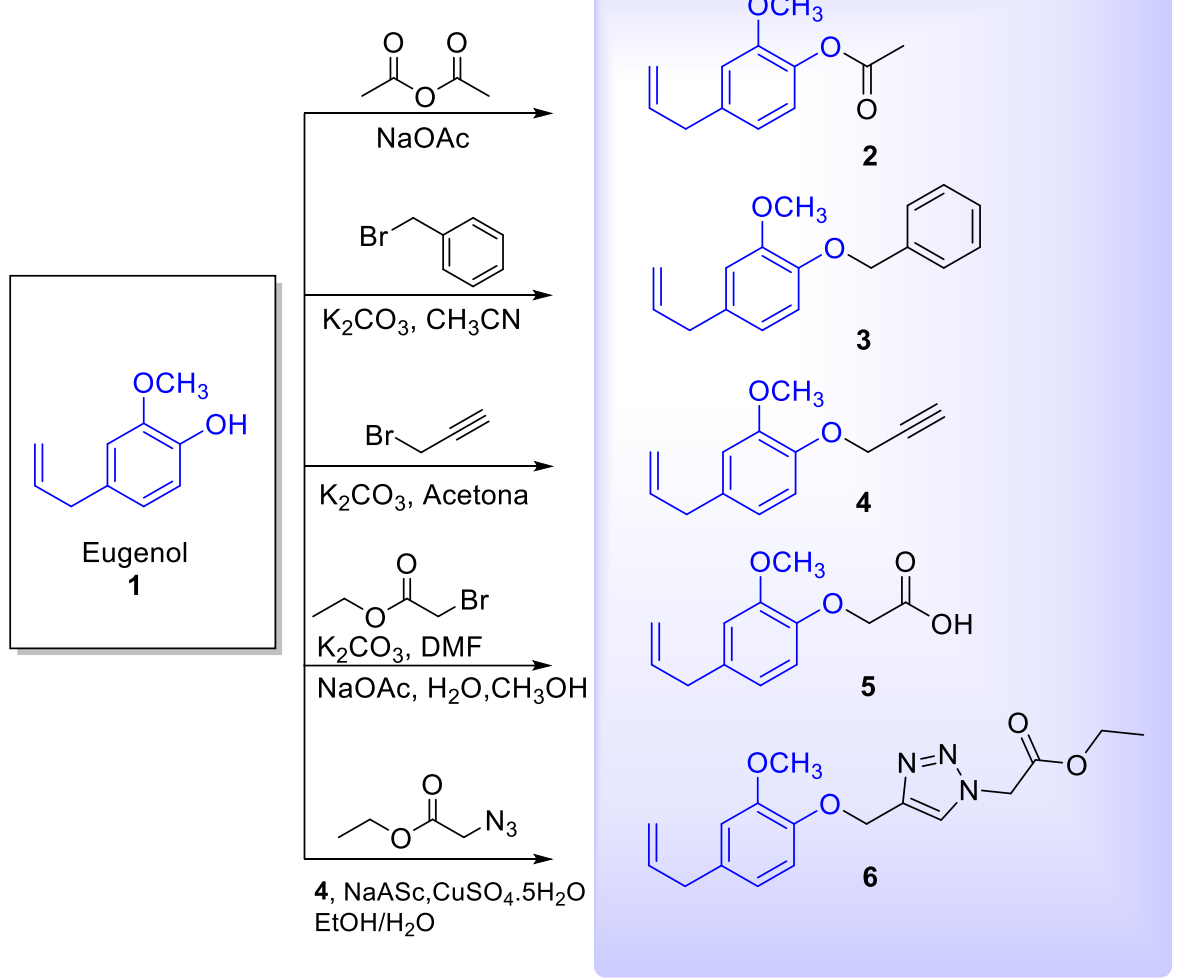

Figura 1: Estrutura do eugenol e Derivados sintetizados.

O composto 6 foi obtido em curto tempo reacional (30 minutos) e com rendimento de $80 \%$. Sua estrutura foi confirmada através de diferentes técnicas espectrométricas. Especificamente, no espectro de infravermelho desse composto, foi observada uma banda fraca em $3137 \mathrm{~cm}^{-1}$ referente ao estiramento da ligação C-H do anel triazólico, sendo esta banda a principal evidencia da formação do anel triazólico conforme descrito por Kaushik et al. (2016) [45]. Além disso, é possível observar as bandas em $3138 \mathrm{~cm}^{-1}$ referente ao estiramento da ligação C-H de carbono $s p^{2}$, e em $2996 \mathrm{~cm}^{-1}$ referente ao estiramento da ligação C-H de carbono $s p^{3}$. Em $1753 \mathrm{~cm}^{-1}$ uma banda intensa atribuída ao grupo carbonila de éster e em $1638 \mathrm{~cm}^{-1}$ uma banda fraca atribuída ao estiramento da ligação $\mathrm{C}=\mathrm{C}$ da porção alílica.

No espectro de RMN ${ }^{1} \mathrm{H}$ do composto 6 foi observado um sinal em 7,75 ppm, na forma de simpleto e integral 1 , o qual foi atribuído ao hidrogênio do anel triazólico, sendo isto outra evidência da formação do anel triazólico. Adicionalmente, Irfan et al. (2015) [46] e Santos et al. (2019) [47] relataram que o hidrogênio do anel 1,2,3-triazólico geralmente apresenta deslocamento químico entre 7,18 a 7,70 ppm. Os demais sinais presentes no espectro de $\mathrm{RMN}{ }^{1} \mathrm{H}$ confirmam a estrutura do composto 6. Por fim, no espectro de RMN ${ }^{13} \mathrm{C}$ do composto 6 foi observado dezessete sinais, valor este correspondente ao número de carbonos quimicamente diferentes presentes na estrutura deste composto.

A avaliação antifúngica do eugenol e seus derivados (2-6) foi realizada através do método de microdiluição em caldo [27] frente a quatro espécies do gênero Candida spp. a citar, Candida albicans, Candida glabrata, Candida parapsilosis e Candida tropicalis. A seleção desse gênero de fungo foi devido à sua prevalência na epidemiologia de infecções fúngicas [48]. Além disso, nos últimos 30 anos, $95 \%$ das infecções fúngicas foram provocadas pelas espécies Candida albicans, C. glabrata, C. parapsilosis, C. tropicalis e C. krusei [49].

Deste modo, a Concentração Inibitória Mínima (CIM), em que representa a menor concentração capaz de inibir visualmente $100 \%$ do crescimento fúngico [37], foi determinada. Os resultados estão descritos na Tabela 1. 
Tabela 1: Concentração inibitória mínima CIM (mM) para o eugenol e seus derivados (1-6).

\begin{tabular}{|c|c|c|c|c|c|c|c|}
\hline \multirow[b]{2}{*}{ Fungos } & \multicolumn{7}{|c|}{ Concentração inibitória mínima CIM (mM) } \\
\hline & Eugenol & 2 & 3 & 4 & 5 & 6 & Anfotericina \\
\hline $\begin{array}{c}\text { Candida albicans } \\
\text { ATCC } 76615\end{array}$ & 0,78 & $>2,48$ & $>2,01$ & $>2,53$ & $>2,3$ & $>1,54$ & 0,001 \\
\hline $\begin{array}{c}\text { Candida glabrata } \\
\text { ATCC } 90030\end{array}$ & 3,12 & $>2,48$ & $>2,01$ & $>2,53$ & $>2,3$ & $>1,54$ & 0,001 \\
\hline $\begin{array}{c}\text { Candida } \\
\text { tropicalis ATCC } \\
13803\end{array}$ & 3,12 & 2,48 & $>2,01$ & 2,53 & $>2,3$ & $>1,54$ & 0,003 \\
\hline $\begin{array}{c}\text { Candida } \\
\text { parapsilosis }\end{array}$ & 1,56 & 2,48 & $>2,01$ & 2,53 & $>2,3$ & $>1,54$ & 0,005 \\
\hline ATCC 22019 & & & & & & & \\
\hline
\end{tabular}

(>) Ausência de inibição na concentração de $512 \mu \mathrm{g} / \mathrm{mL}$.

Constatou-se que o eugenol apresentou inibição para todas as cepas de fungos avaliadas com os seguintes valores de CIM de 0,78 a 3,12 mM. Este resultado está de acordo com os trabalhos descritos na literatura [50-52], os quais enfatizam a ação antifúngica do eugenol e sua atuação como inibidor da biossíntese do ergosterol, constituinte essencial da membrana fúngicas [50].

Os derivados 2 e $\mathbf{4}$ apresentaram valores de CIM equiparáveis ao do eugenol (Tabela 1) para a espécie de Candida tropicalis. Em contrapartida os derivados 3, 5 e 6, não apresentaram inibição do crescimento fúngico na concentração máxima testada de $512 \mu \mathrm{g} / \mathrm{mL}$, o que indica que a incorporação de um anel aromático, heteroaromático ou grupo alquilico não favoreceu a ação antifúngica desses derivados. Adicionalmente, os compostos 2-6 apresentam nenhuma ou pouca atividade microbiana quando comparado ao padrão anfotericina.

Diante dos valores de CIM do eugenol e do composto 6, buscou-se compreender os fatores que poderiam justificar a ausência da atividade antifúngica do composto $\mathbf{6}$ na concentração máxima testada, uma vez que este composto apresenta em sua estrutura um anel triazólico, unidade bastante relatada pois está presente em diversos fármacos amplamente aplicados no tratamento dos quadros infecciosos, a citar o fluconazol, o voriconazol, itraconazol e posaconazol [53, 54].

Nesse sentido, foi realizado o estudo de docking molecular envolvendo o composto 6 e a enzima esterol $14 \alpha$-desmetilase (CYP51). Esta enzima foi escolhida devido atuar como alvo antifúngico de vários fármacos, em especial os triazóis $[55,56]$.

A validação dos parâmetros utilizados nos estudos de docking molecular foi realizada através da avaliação do redocking para o posaconazol, obtendo-se um valor de RMSD de 1,39 A, atestando a eficiência dos parâmetros utilizados. Como mostrado na Tabela 2, o docking molecular apresentou uma energia livre de ligação para o composto 6 superior quando comparada com o fármaco posaconazol, indicando que este composto não interage com a enzima CYP51 com características termodinâmicas semelhante ao posaconazol.

A análise do docking dos compostos 6 e do posacanazol com a enzima CYP51 demonstra que ambos são capazes de interagir com o sítio ativo desse alvo molecular (Figura 2), entretanto o composto $\mathbf{6}$ apresenta particularmente uma interação desfavorável do tipo Unfavorable Conflict of Acceptors (Conflito Desfavorável de Aceptores), a qual é estabelecida entre o grupo carbonila do composto 6 e o grupo carbonila presente no aminoácido serina 378 (SER:378) (Figura 3). Esta interação desfavorável é devido à aproximação entre os átomos de oxigênio dos grupos carbonilas desses compostos a uma distância de 2,80 Å (uma distância menor que a soma dos raios de van der Walls desses átomos $=3,04 \AA$ ), em que as cargas negativas parciais se repelem forçando uma repulsão desta porção do composto 6 parte para fora do sítio ativo da enzima, dando origem a uma conformação energeticamente desfavorável [57]. 
Tabela 2: Energias livres de ligação encontradas para composto 6 e para o posaconazol frente a enzima CYP51.
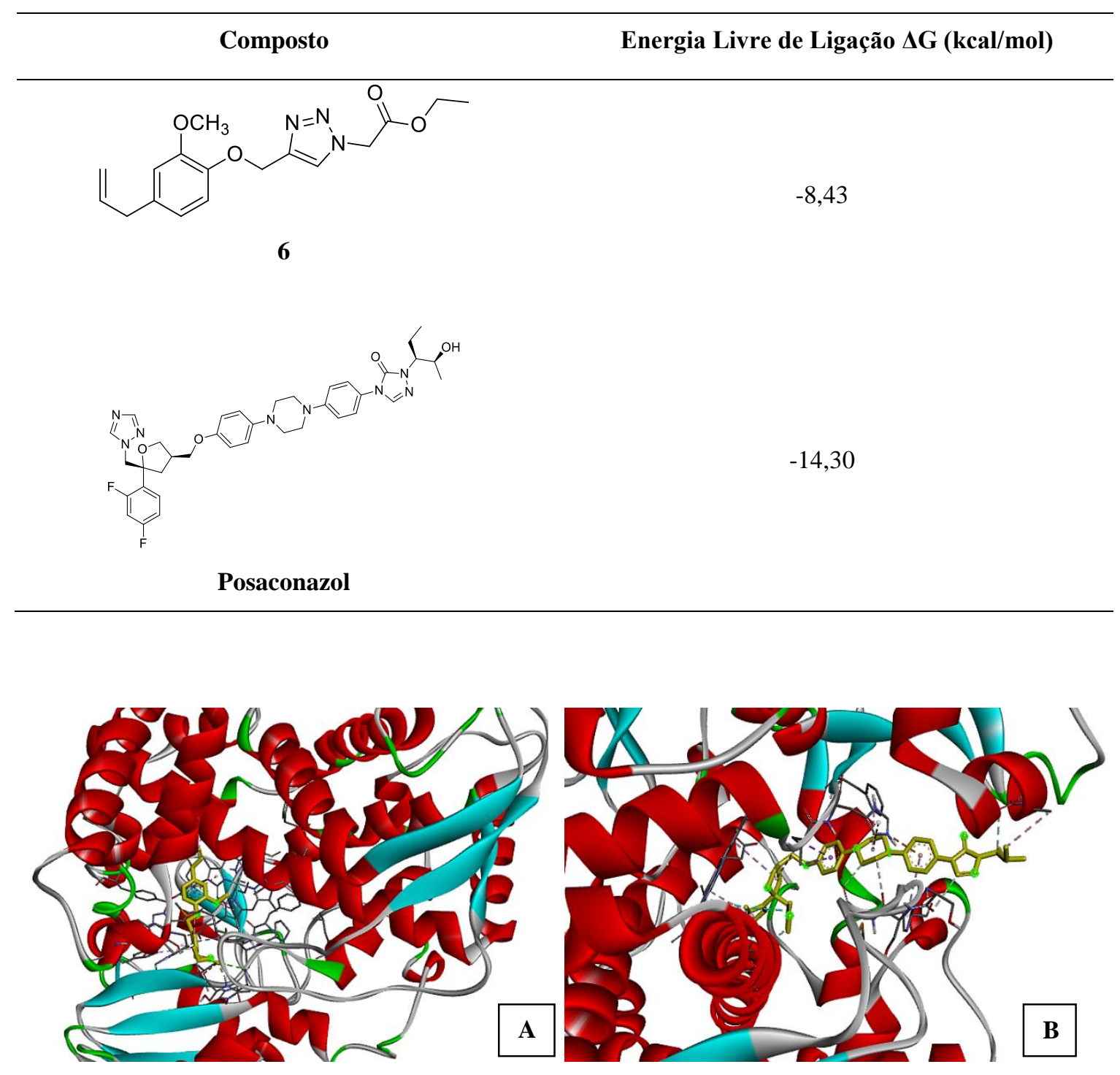

Figura 2: Modos de ligação dos compostos ancorados (em amarelo) à enzima CYP51. A) Interação entre o composto 6 e a enzima CYP51. B) Interação entre posaconazol e a enzima CYP51.

Vale ressaltar que o composto 6 também estabelece interações favoráveis com a enzima CYP51 a citar: ligações de hidrogênios com os resíduos de HIS:377 e TYR:118 e interações hidrofóbicas do tipo Pi-Sigma, Pi-Alquil, Alquil e Pi-Pi empilhada (Figura 3). Os resíduos de aminoácidos da enzima CYP51 que interagem com o composto 6 e o posaconazol estão descritas na Tabela 3. 


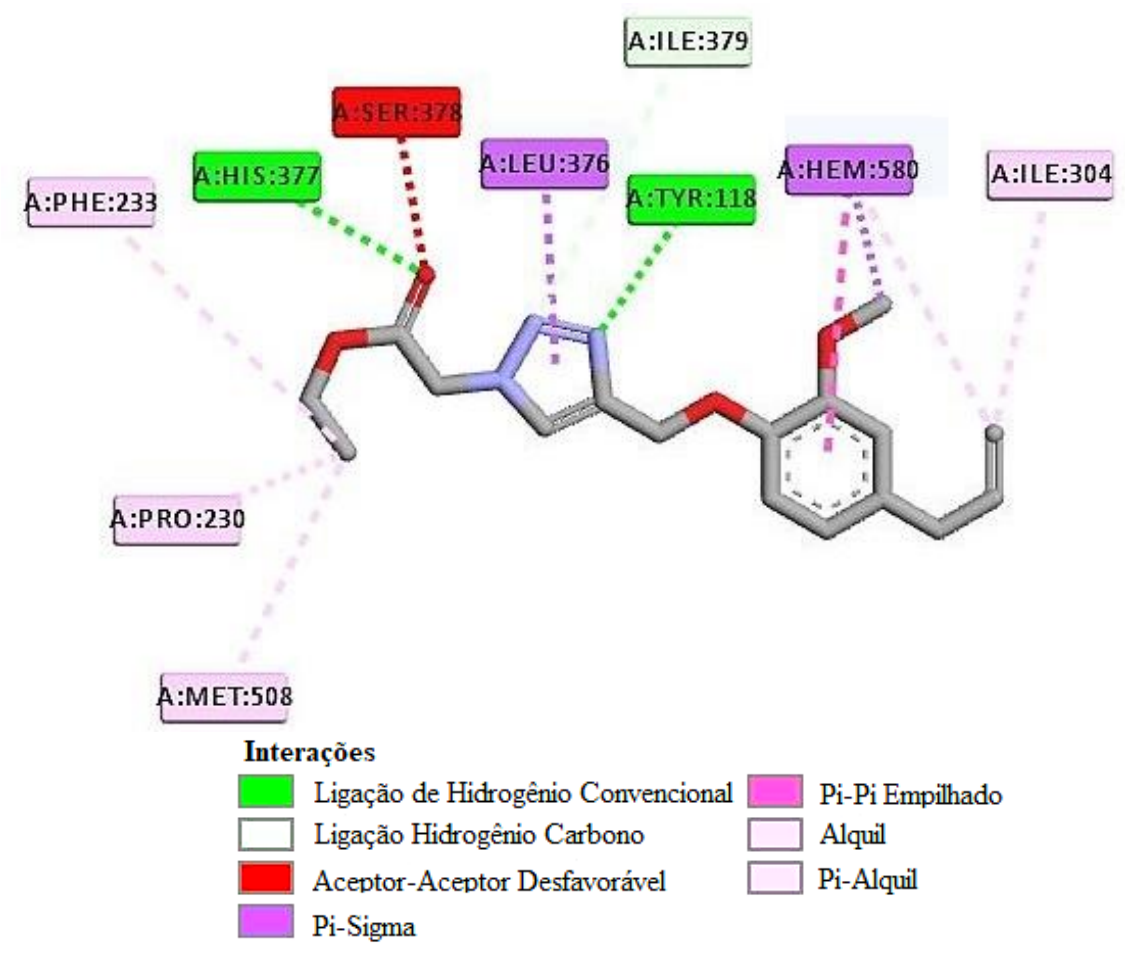

Figura 3: Representação 2D das interações intermoleculares entre o composto 6 e a enzima CYP51.

Tabela 3: Aminoácidos da enzima CYP51 envolvidos na interação com o composto 6 e o posaconazol.

\begin{tabular}{cc} 
Composto & Resíduos de aminoácidos \\
\hline 6 & TYR:118, PRO:230, PHE:233, ILE:304, LEU:376, \\
& HIS:377, SER:378, ILE:379, MET:508 \\
& PHE:58, ALA:61, ALA:62, TYR:64, GLY:65, \\
& LEU:88, TYR:118, LEU:121, THR:122, PHE:126, \\
& ILE:131, TYR:132, PHE:228, PRO:230, PHE:233, \\
& GLY:303, ILE:304, GLY:307, GLY:308, THR:311, \\
& LEU:376, HIS:377, SER:378, PHE:380, TYR:505, \\
& SER:506, SER:507, MET:508 \\
\hline
\end{tabular}

${ }^{a}$ Fonte: Hargrove et al. (2017) [41].

Conforme apresentado na Tabela 3, boa parte dos resíduos previstos para o composto 6 também estão envolvidos na interação com o posaconazol. Entretanto, cabe ressaltar que o composto 6 apresentou uma menor quantidade de interação com a enzima CYP51, quando comprado com o posacanazol, conforme apresentado na Tabela 3. Desta forma, o menor número de interações e a presença de interações desfavoráveis relatadas nos resultados de docking molecular permitem vislumbrar alguns motivos que justificam a ausência da atividade antifúngica do composto 6. Por fim, tais resultados são o primeiro passo no desenvolvimento de novos medicamentos, fornecendo informações importantes que ajudarão na condução de pesquisas futuras envolvendo estes compostos e seus derivados. 


\section{CONCLUSÃO}

De modo geral, foram sintetizados cinco derivado do eugenol com bons rendimentos que variaram de $80-95 \%$ por meio de modificações na hidroxila fenólica. A avaliação da atividade antifúngica demonstrou que alguns derivados do eugenol apresentaram atividade $(2$ e 4) enquanto, outras modificações levaram a ausência da mesma $(\mathbf{3}, \mathbf{5}$ e 6). Através do docking molecular foi possível sugerir fatores moleculares que possam ter colaborado para a ausência da atividade antifúngica notada no derivado do eugenol 1,2,3-triazólico, o qual não interage com a enzima CYP51 com características termodinâmicas semelhante ao posaconazol. Esses resultados são estudos preliminares que trazem informações importantes que ajudarão na condução de pesquisas futuras envolvendo estes compostos e seus derivados.

\section{AGRADECIMENTOS}

Os autores agradecem às agências de fomento CNPq (434012/2018-1) ao PRONEM/FACEPE (APQ-0476-1.06/14) pelo suporte financeiro, a FACEPE (IBPG-1331-1.06/16; IBPG-00941.06/17) pelas bolsas concedidas e a Central Analítica do DQF-UFPE pelas análises concedidas.

\section{REFERÊNCIAS BIBLIOGRÁFICAS}

1. Brown GD, Denning DW, Levitz SM. Tackling Human Fungal Infections. Science. 2012 Mai;336(6082):647, doi: 10.1126/science.1222236.

2. Teodoro GR, Brighenti FL, Delbem AC, Delbem ÁC, Khouri S, Gontijo AV, Pascoal AC, Salvador MJ, koga-ito CY. Antifungal activity of extracts and isolated compounds from Buchenavia tomentosa on Candida albicans and non-albicans. Future Microbiol. 2015;10(6):917-27, doi: 10.2217/fmb.15.20.

3. Kullberg BJ, Arendrup MC. Invasive Candidiasis. N Engl J Med. 2015;373(15):1456-1445, doi: 10.1056/NEJMra1315399.

4. Whaley SG, Berkow EL, Rybak JM, Nishimoto AT, Barker KS, Rogers PD. Azole Antifungal Resistance in Candida albicans and Emerging Non-albicans Candida Species. Front Microbiol. 2017 Jan;7:2173, doi: 10.3389/fmicb.2016.02173.

5. Silva AF, Silva DA. Fármacos anti-inflamatórios não esteroidais mais dispensados em uma farmácia comercial do município de itaocara, estado do rio de janeiro, brasil. Acta Biomed Bras. 2012;3(2): 1-14.

6. Cortés JA, Corrales FI. Infecção fúngica. 1 ed. London: editors IntechOpe; 2018. Chapter 3, Invasive Candidiasis: Epidemiology and Risk Factors; p. 1-24, doi: 10.5772/intechopen.81813.

7. Toutounji M, Tokajian S, Khalaf RA. Genotypic and phenotypic characterization of Candida albicans Lebanese hospital isolates resistant and sensitive to caspofungin. Fungal Genet Biol. 2019 Fev;127:2212, doi: 10.1016/j.fgb.2019.02.008.

8. Wiederhold NP. Antifungal resistance: current trends and future strategies to combat. Infect Drug Resist. 2017 Ago;10:259-249, doi: 10.2147/IDR.S124918.

9. Pfaller MA, Castanheira M, Lockhart SR, Ahlquist AM, Messer SA, Jones RN. Frequency of Decreased Susceptibility and Resistance to Echinocandins among Fluconazole-Resistant Bloodstream Isolates of Candida glabrata. J Clin Microbiol. 2012;50(4):1203-1199, doi: 10.1128/JCM.06112-11.

10. Sanglarda D, Odds FC. Resistance of Candida species to antifungal agents: molecular mechanisms and clinical consequences. Infect Dis. 2002 Fev;2(2):85-73, doi: 10.1016/s1473-3099(02)00181-0.

11. Chouhan S, Sharma KE, Guleria S. Antimicrobial Activity of Some Essential Oils-Present Status and Future Perspectives. Medicines. 2017 Ago;4(3):58, doi: 10.3390/medicines4030058.

12. Cowen LE, Sanglard D, Howard SJ, Rogers PD, Perlin DS. Mechanisms of Antifungal Drug Resistance. Cold Spring Harb. Perspect Med. 2015 Nov;5(7):1-22, doi: 10.1101/cshperspect.a019752.

13. Kathiravan MK, Salake AM, Chothe AS, Dudhe PB, Watode RP, Mukta MS, Gadhwe S. The biology and chemistry of antifungal agents: A review. Bioorg Med Chem. 2012 Out;20(19):5678-98, doi: 10.1016/j.bmc.2012.04.045.

14. Carvalho LIS, Alvarenga DJ, Carmo LCF, Oliveira LG, Silva NC, Dias ALT, Coelho LFL, Souza TB, Dias DF, Carvalho DT. Antifungal Activity of New Eugenol-Benzoxazole Hybrids against Candida spp. J Chem. 2017 Jul;2017:8-1, doi: 10.1155/2017/5207439.

15. Marchese A, Barbieri R, Coppo E, Orhan IE, Daglia M, Nabavi SF, Izadi M, Abdollahi M, Nabavi SM, Ajami M. Antimicrobial activity of eugenol and essential oils containing eugenol: A mechanistic viewpoint. Critical Rev Microbiol. 2017;43(6):668-689, doi: org/10.1080/1040841X.2017.1295225. 
16. Lima JAC, Freitas JR, Silva JF, Filho MC, Freitas JCR. O Estado da Técnica do Eugenol: Uma Prospecçao Tecnológica Fundamentada em Base de Dados de Patentes e Periódicos. Rev Virtual Quim. 2019 Jul;11(3):719-699, doi: 10.21577/1984-6835.20190052.

17. Kaufman TS. The Multiple Faces of Eugenol. A Versatile Starting Material and Building Block for Organic and Bio-Organic Synthesis and a Convenient Precursor Toward Bio-Based Fine Chemicals. J Braz Chem Soc. 2015;26(6):1055-1085, doi: 10.5935/0103-5053.20150086.

18. Chatterjee D, Bhattacharjee P. Use of eugenol-lean clove extract as a flavoring agent and natural antioxidant in mayonnaise: product characterization and storage study. J Food Sci Technol. 2015 Ago;52(8):4954-4945, doi: 10.1007/s13197-014-1573-6.

19. Kamatou GP, Vermaak I, Viljoen AM. Eugenol-From the Remote Maluku Islands to the International Market Place: A Review of a Remarkable and Versatile Molecule. Molecules 2012;17(6):6981-6953, doi: 10.3390/molecules17066953.

20. Gomes AL, Gomes PS, Sampaio-Fernandes JC, Leal C, Pinho A. Materiais de Resina e Superfícies Contaminadas com Eugenol. Med Dent Cirur Maxilofac. 2006;47(2):115-107.

21. Wan J, Gan B, Li C, Molina-Aldareguia J, Kalali EN, Wang X, Wang D. A sustainable, eugenol-derived epoxy resin with high biobased content, modulus, hardness and low flammability: Synthesis, curing kinetics and structure-property relationship. Chem Eng J. 2016 Jan;284:1093-1080, doi: 10.1016/j.cej.2015.09.031.

22. Silva FFM, Monte FJQ, Lemos TLG, Nascimento PGG, Costa AKM, Paiva LMM. Eugenol derivatives: synthesis, characterization, and evaluation of antibacterial and antioxidant activities. Chem Cent J. 2018; 12(1):43-34, doi: 10.1186/s13065-018-0407-4.

23. Knop LB, Maria DA, Métodos substitutivos e a experimentação animal: um enfoque inovador. Rev Soc Bras Ci Anim Lab. 2017;4(2):101-114,

24. Santos CEM, Rodrigues AS, Toxicologia in silico: contexto de aplicação e o modelo de custo-efetividade nos testes alternativos. Rev Intertox Toxicol, Risco Amb Soc. 2011;4(3):92-113, doi: 10.22280/revintervol4ed3.97.

25. Katsila T, Spyroulias GA, Patrinos GP, Matsoukas M. Computational approaches in target identification and drug discovery. Comput. Struct. Biotechnol. J. 2016 14:184-177, doi: 10.1016/j.csbj.2016.04.004.

26. Piccirillo E, do Amaral AE. Busca virtual de compostos bioativos: conceitos e aplicações. Quim Nova. 2018;41(6):677-662, doi: 10.21577/0100-4042.20170210.

27. CLSI. Reference Method for Broth Dilution Antifungal Susceptibility Testing of Yeasts, Approved Standard- Third Edition. CLSI document M27-A3. Wayne, PA: Clinical and Laboratory Standards Institute; 2008.

28. Olea AF, Bravo A, Martínez R, Thomas M, Sedan C, Espinoza L, Zambrano L, Carvajal D, Silva-Moreno E, Carrasco H. Antifungal Activity of Eugenol Derivatives against Botrytis cinerea. Molecules. 2019; 24(7):1239, doi:10.3390/molecules24071239.

29. Khan SN, Khan S, Misba L, Sharief M, Khan AU. Synergistic fungicidal activity with low doses of eugenol and amphotericin B against Candida albicans. Biochem Biophys Res Comm. 2019; 518(3):459464, doi: 10.1016/j.bbrc.2019.08.053.

30. Jeyabaskar S, Sharanya M, Mahendran R, Neha S, Astral F. Identification and Analysis of Natural Compounds as Fungal Inhibitors from Ocimum sanctum using in silico Virtual Screening and Molecular Docking. Res J Pharm Technol. 2017;10(10):3369-3374, doi: 10.5958/0974-360X.2017.00599.6.

31. Lone SA, Khan S, Ahmad A. Inhibition of ergosterol synthesis in Candida albicans by novel eugenol tosylate congeners targeting sterol 14 $\alpha$-demethylase (CYP51) enzyme. Arch Microbiol. 2020; 202(4):711-726, doi: 10.1007/s00203-019-01781-2.

32. Ben Arfa A, Combes S, Preziosi-Belloy L, Gontard N, Chalier P, Antimicrobial activity of carvacrol related to its chemical structure. Lett Appl Microbiol. 2006;43(2):149-154, doi: 10.1111/j.1472765X.2006.01938.x.

33. Vijendra Kumar N, Srinivas P, Bettadaiah BK. New scalable and eco-friendly synthesis of gingerols. Tetrahedron Letters. 2012;53(24):2993-2995, doi:10.1016/j.tetlet.2012.03.092.

34. He J, Feng L, Li J, Tao R, Wang F, Liao X, Sun Q, Long Q, Ren Y, Wan J, He H. Design, synthesis and biological evaluation of novel 2-methylpyrimidine-4-ylamine derivatives as inhibitors of Escherichia coli pyruvate dehydrogenase complex E1 Bioorg Med Chem. 2012;20(5):1665-1670, doi:10.1016/j.bmc.2012.01.019.

35. Buckler JN, Banwell MG, Kordbacheh F, Parish CR, Santiago FS, Khachigian LM. Developing Neolignans as Proangiogenic Agents: Stereoselective Total Syntheses and Preliminary Biological Evaluations of the Four Guaiacylglycerol 8-O-4'-Coniferyl Ethers. ACS Omega. 2017;2(10):7375-7388. doi:10.1021/acsomega.7b01459. 
36. Teixeira RR, Gazolla PAR, Da Silva AM, Borsodi MPG, Bergmann BR, Ferreira RS, Vaz BG, Vasconcelos GA, Lima WP. Synthesis and leishmanicidal activity of eugenol derivatives bearing 1,2,3triazole functionalities. Eur J Med Chem. 2018;146:274-286, doi: 10.1016/j.ejmech.2018.01.046.

37. EspineL-Ingroff A, Fothergill A, Ghannoum M, Manavathu E, Ostrosky Zeichner L, Pfaller M, Rinaldi M, Schell W, Walsh T. Quality control and reference guidelines for CLSI broth microdilution susceptibility method (M 38-A document) for amphotericin B, itraconazole, posaconazole, and voriconazole. J Microbiol. 2005 Out;43(10):5243-6, doi: 10.1128/JCM.43.10.5243-5246.2005.

38. Hanwell MD, Curtis DE, Lonie DC, Vandermeerschd T, Zurek E, Hutchison GRJ. Avogadro: an advanced semantic chemical editor, visualization, and analysis platform. Cheminform. 2012 Ago;4(1)4917, doi: 10.1186/1758-2946-4-17.

39. Stewart JJP. Optimization of parameters for semiempirical methods V: Modification of NDDO approximations and application to 70 elements. J Mol Model. 2007 Set;13:1213-1173.

40. http://openmopac.net/, acessado em novembro 2019.

41. Hargrove TY, Friggeri L, Wawrzak Z, Qi A, Hoekstra WJ, Schotzinger RJ, York JD, Guengerich FP, Lepesheva GI. Structural analyses of Candida albicans sterol $14 \alpha$-demethylase complexed with azole drugs address the molecular basis of azole-mediated inhibition of fungal sterol biosynthesis. J Biol Chem. 2017 Abr;292(16):6743-6728, doi: 10.1074/jbc.M117.778308.

42. https://www.3dsbiovia.com/, acessado em novembro 2019.

43. Barbosa JD, Silva VB, Alves PB, Gumina G, Santos RL, Sousa DP, Cavalcanti SC. Structure-activity relationships of eugenol derivatives against Aedes aegypti (Diptera: Culicidae) larvae. Pest Manag Sci. 2012 Nov;68(11):1478-83, doi: 10.1002/ps.3331.

44. Hamri S, Aboulas A, El Ammari I, Fadel S, Hafid A, El Haddad M, Noureddine K, Lazar S, Pujol MD, Khouili M. Synthesis of new derivatives of 4,5-dihydro-1h-pyrazole via 4-allyl-2-methoxyphenol. J Marocain Chimie Heterocyclique. 2009 Dec;8(1):28-34.

45. Kaushik CP, Kumar K, Singh SK, Singh D, Saini S. Synthesis and antimicrobial evaluation of 1,4disubstituted 1,2,3-triazoles with aromatic ester functionality. Arabian J Chem. 2016 Nov;9(6):871-865, doi: 10.1016/j.arabjc.2013.09.023.

46. Irfan M, Aneja B, Yadava U, Khan SI, Manzoor N, Daniliuc CG, Abid M. Synthesis, QSAR and anticandidal evaluation of 1,2,3-triazoles derived from naturally bioactive scaffolds. Eur J Med Chem. 2015 Mar;93:246-54, doi: 10.1016/j.ejmech.2015.02.007.

47. Santos T, Coelho CM, Elias TC, Siqueira FS, Nora ESSD, Campos MMA, Souza GAP, Coelho IFL, Carvalho D T. Synthesis and Biological Evaluation of New Eugenol-Derived 1,2,3- Triazoles as Antimyco bacterial Agents. J Braz Chem Soc. 2019;30(7):1436-1425, doi: 10.21577/01035053.20190038.

48. Whaley SG, Berkow EL, Rybak JM, Nishimoto AT, Barker KS, Rogers PD. Azole Antifungal Resistance in Candida albicans and Emerging Non-albicans Candida Species. Front Microbiol. 2017;7:2173, doi: 10.3389/fmicb.2016.02173.

49. Yap PSX, Yiap BC, Ping HC, Lim SHE. Essential oils, a new horizon in combating bacterial antibiotic resistance. Open Microbiol J. 2014 Fev;8:14-6, doi: 10.2174/1874285801408010006.

50. Ahmad A, Khan A, Khan LA, Manzoor N. In vitro synergy of eugenol and methyleugenol with fluconazole against clinical Candida isolates. J Med Microbiol. 2010 Out;59(10):1178-84, doi: 10.1099/jmm.0.020693-0.

51. Carrasco H, Raimondi M, Svetaz LM, Di Liberto L, Rodriguez MV, Espinoza L, Madrid A. Antifungal Activity of Eugenol Analogues. Influence of Different Substituents and Studies on Mechanism of Action. Molecules. 2012;17(1):1024-1002, doi: 10.3390/molecules17011002.

52. Ahmad A, Wani MY, Khan A, Manzoor N, Molepo J. Synergistic Interactions of Eugenol tosylate and Its Congeners with Fluconazole against Candida albicans. Plos One. 2015;10(12):19-1, doi: 10.1371/journal.pone.0145053.

53. Pore VS, Agalave SG, Singh P, Shukla PK, Kumar V, Siddiqi MI. Design and synthesis of new fluconazole analogues. Org Biomol Chem. 2015;13:6561-6551, doi: 10.1039/C5OB00590F.

54. Irfan M, Alam S, Manzoor N, Abid M. Effect of quinoline based 1,2,3-triazole and its structural analogues on growth and virulence attributes of Candida albicans. Plos One. 2017;12(4):e0175710, doi: 10.1371/journal.pone.0175710.

55. Maertens JA. History of the development of azole derivatives. Clin Microbiol Infect. 2004;10:10-1, doi: 10.1111/j.1470-9465.2004.00841.x.

56. Emami S, Tavangar P, Keighobadi M. An overview of azoles targeting sterol $14 \alpha$-demethylase for antileishmanial therapy. Eur J Med Chem. 2017;135:259-241, doi: 10.1016/j.ejmech.2017.04.044.

57. Deepak RNVK, Sankararamakrishnan R. Unconventional N-H...N Hydrogen Bonds Involving Proline Backbone Nitrogen in Protein Structures Biophys J. 2016;110(9)1979-1967, doi: 10.1016/j.bpj.2016.03.034. 


\section{MATERIAL SUPLEMENTAR}

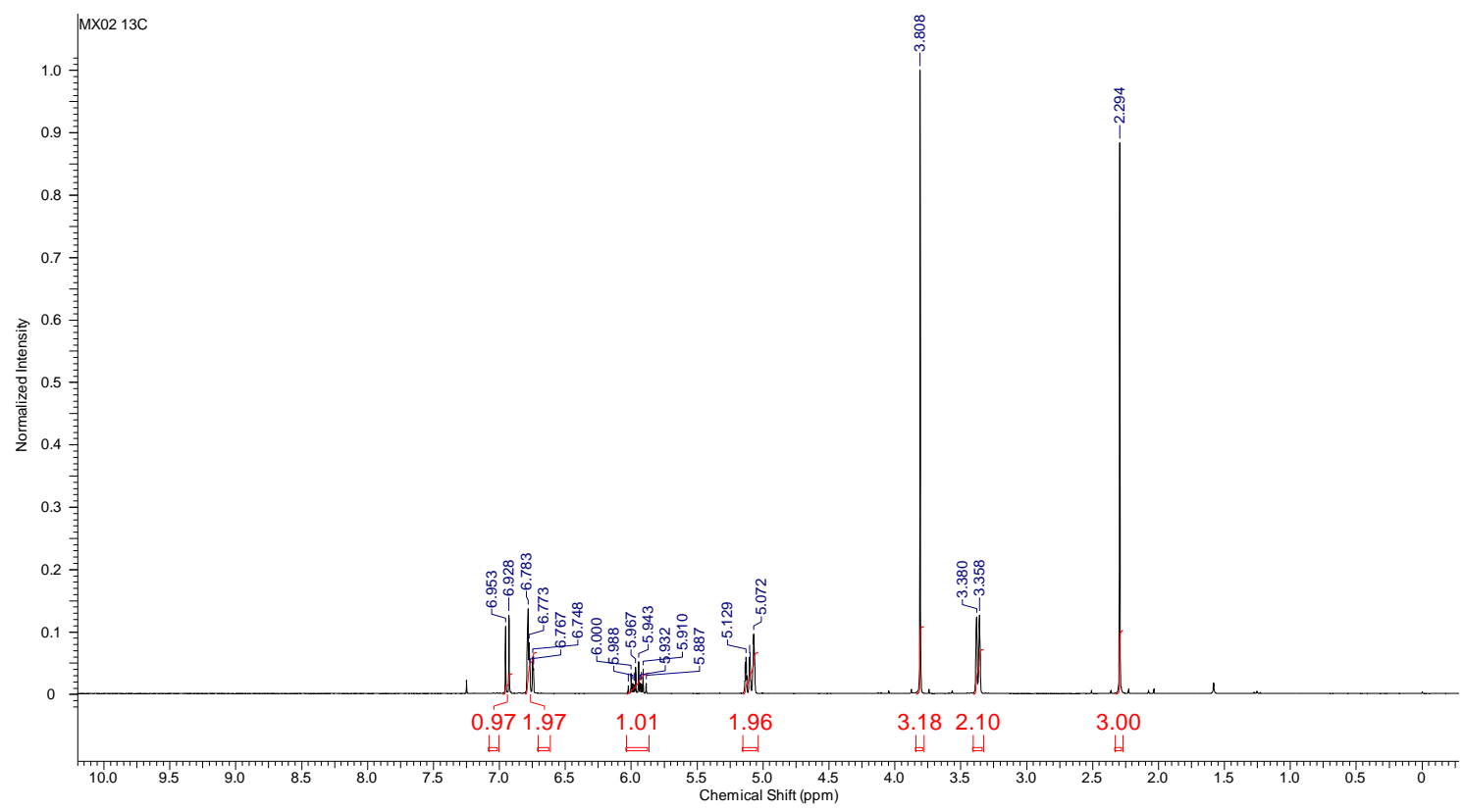

Figura 1S: Espectro de $\mathrm{RMN}^{1} \mathrm{H}\left(300 \mathrm{MHz}, \mathrm{CDCl}_{3}\right)$ do composto 2.

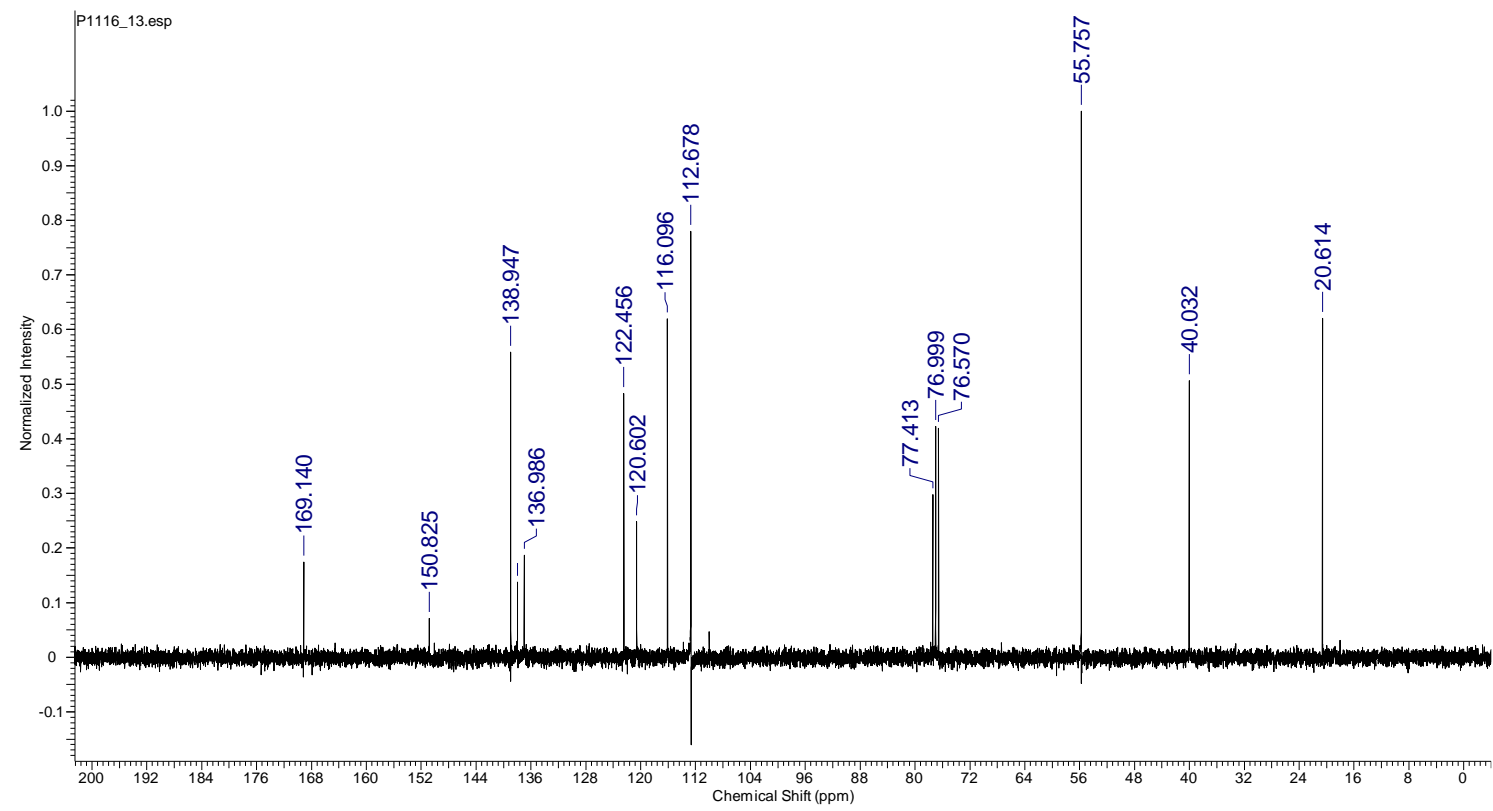

Figura 2S: Espectro de $\mathrm{RMN}^{13} \mathrm{C}\left(75 \mathrm{MHz}, \mathrm{CDCl}_{3}\right)$ do composto 2. 


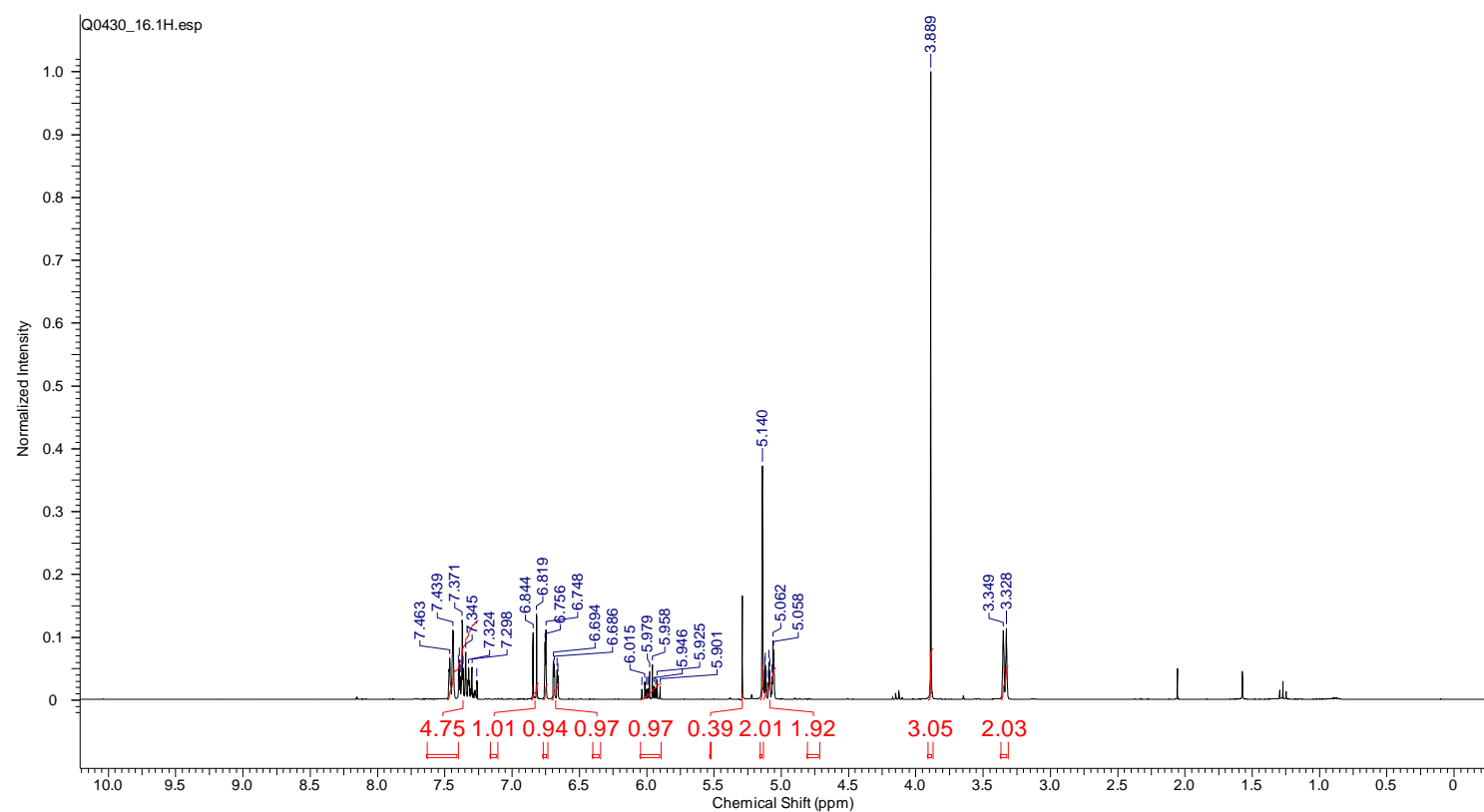

Figura 3S: Espectro de $\mathrm{RMN}^{1} \mathrm{H}\left(300 \mathrm{MHz}, \mathrm{CDCl}_{3}\right)$ do composto 3 .

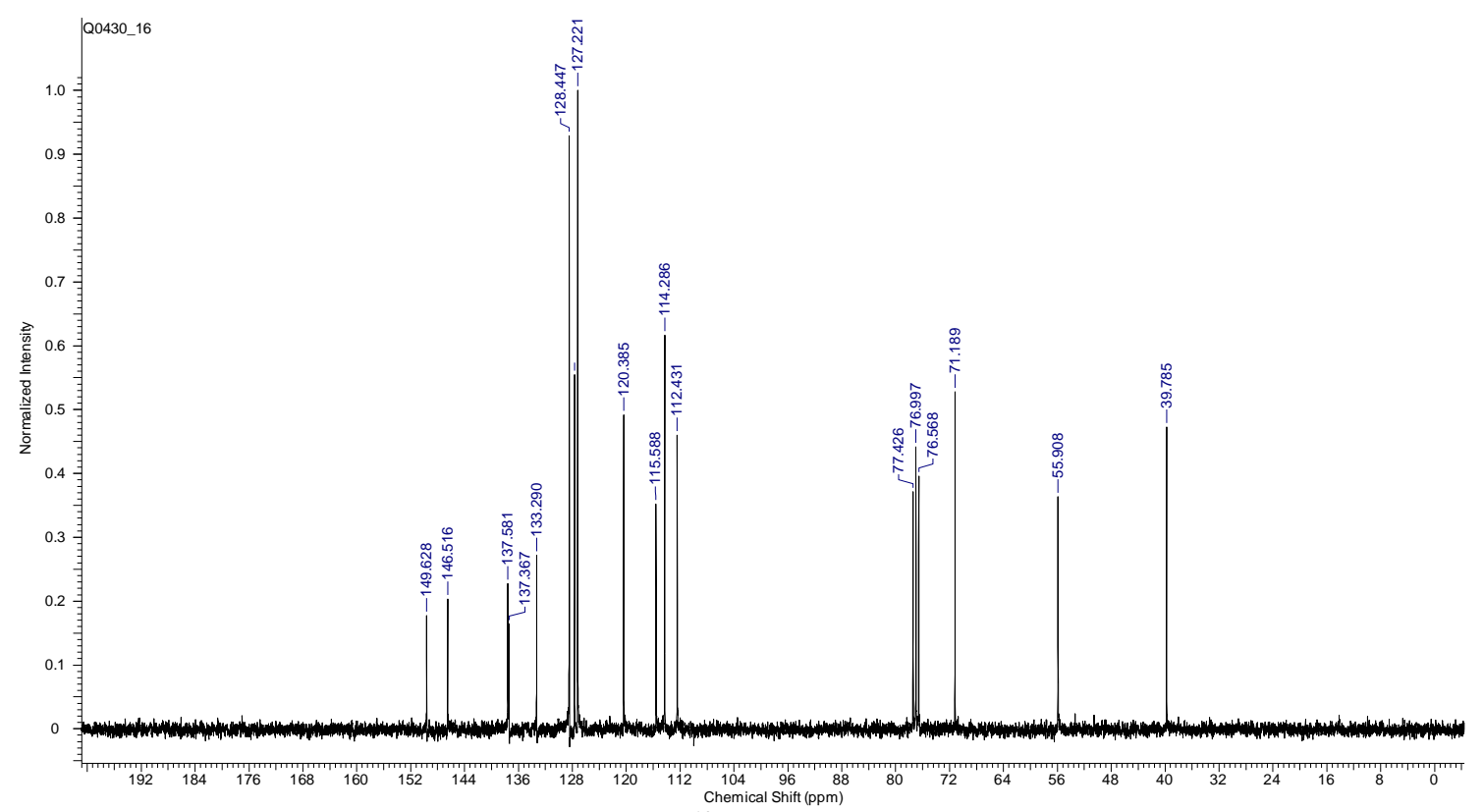

Figura 4S: Espectro de $\mathrm{RMN}^{13} \mathrm{C}\left(75 \mathrm{MHz}, \mathrm{CDCl}_{3}\right)$ do composto 3. 


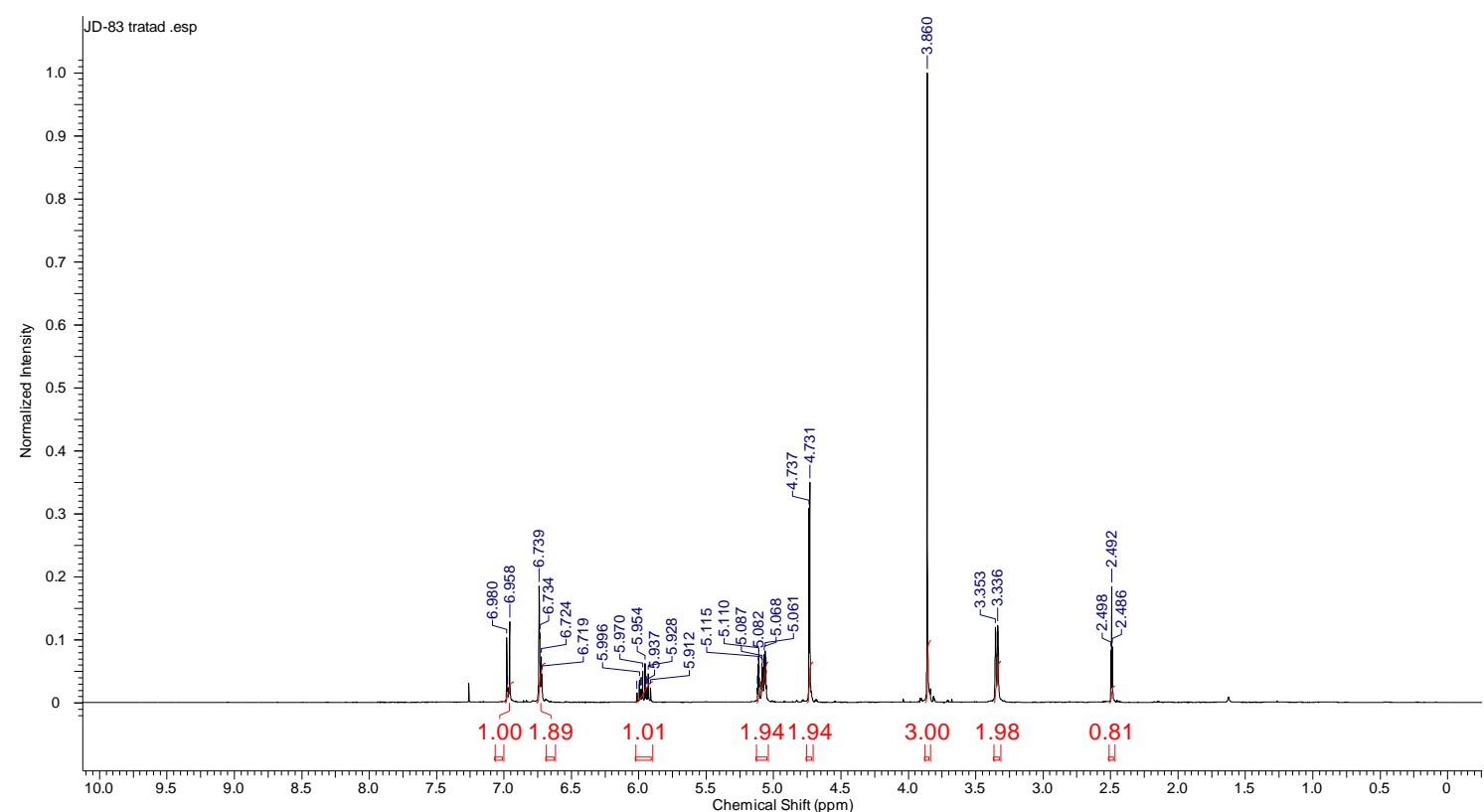

Figura 5S: Espectro de $\mathrm{RMN}^{1} \mathrm{H}\left(400 \mathrm{MHz}, \mathrm{CDCl}_{3}\right)$ do composto 4.

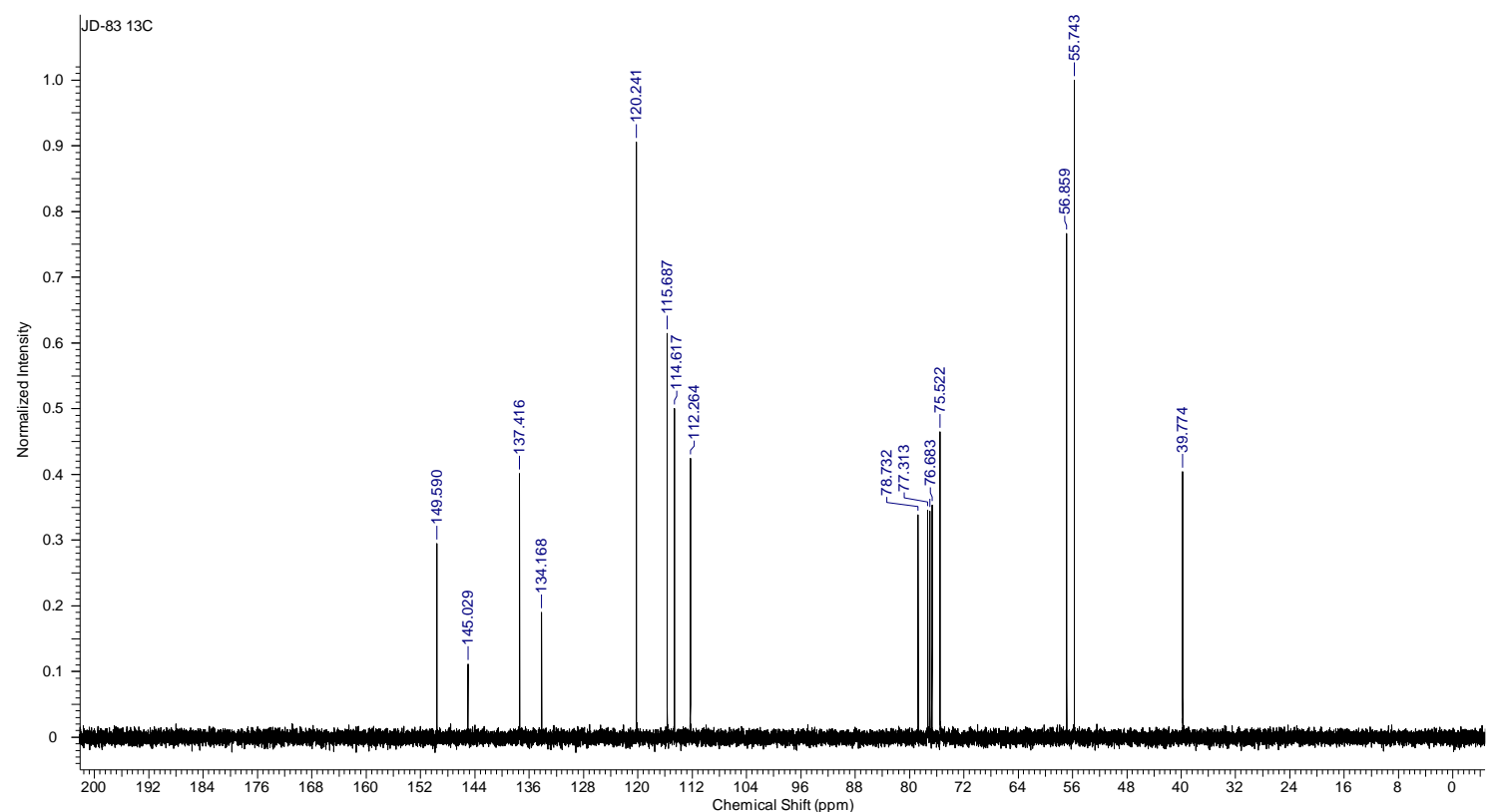

Figura 6S: Espectro de $\mathrm{RMN}^{13} \mathrm{C}\left(100 \mathrm{MHz}, \mathrm{CDCl}_{3}\right)$ do composto 4. 


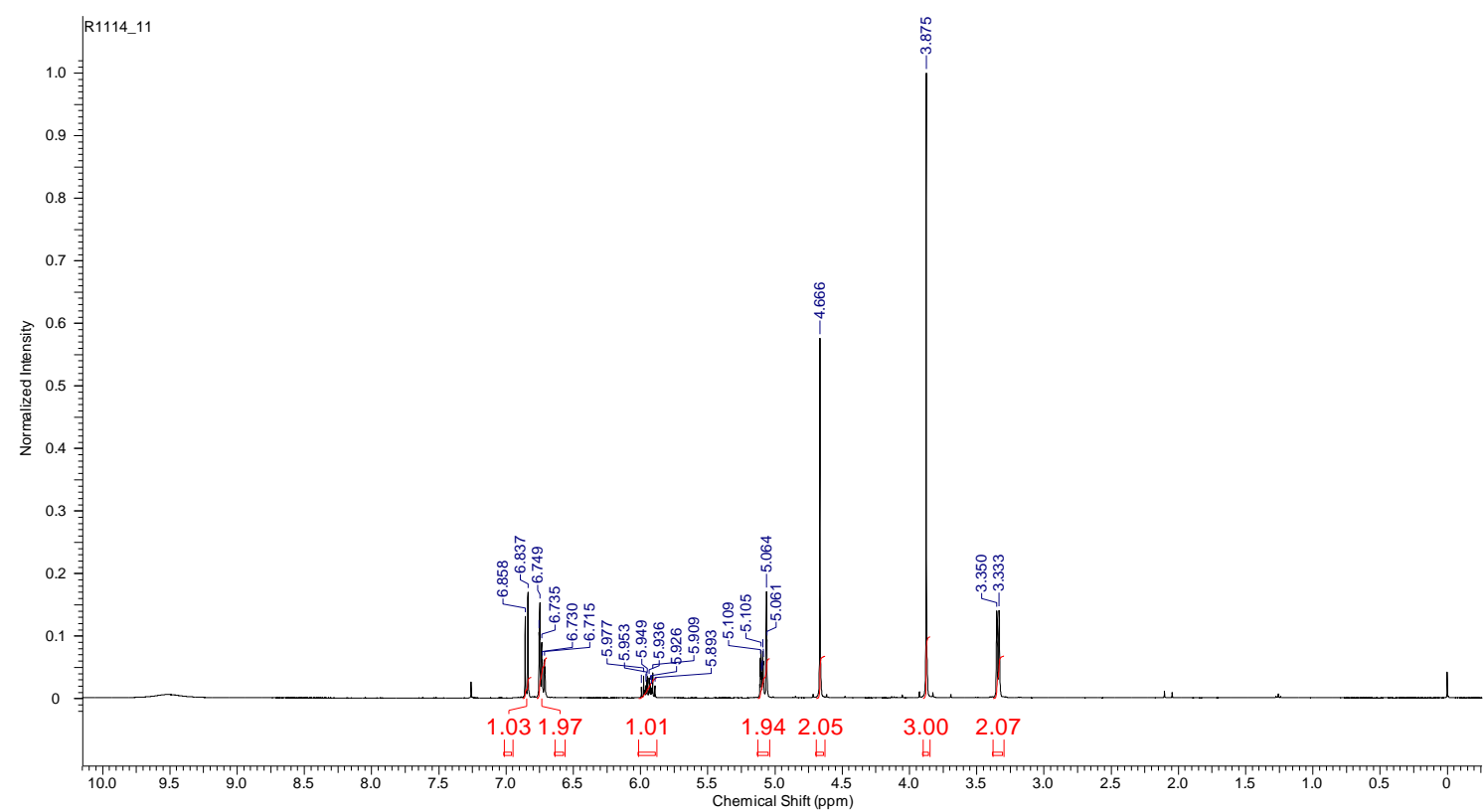

Figura $7 \mathrm{~S}$ : Espectro de $\mathrm{RMN}{ }^{1} \mathrm{H}\left(400 \mathrm{MHz}, \mathrm{CDCl}_{3}\right)$ do composto 5.

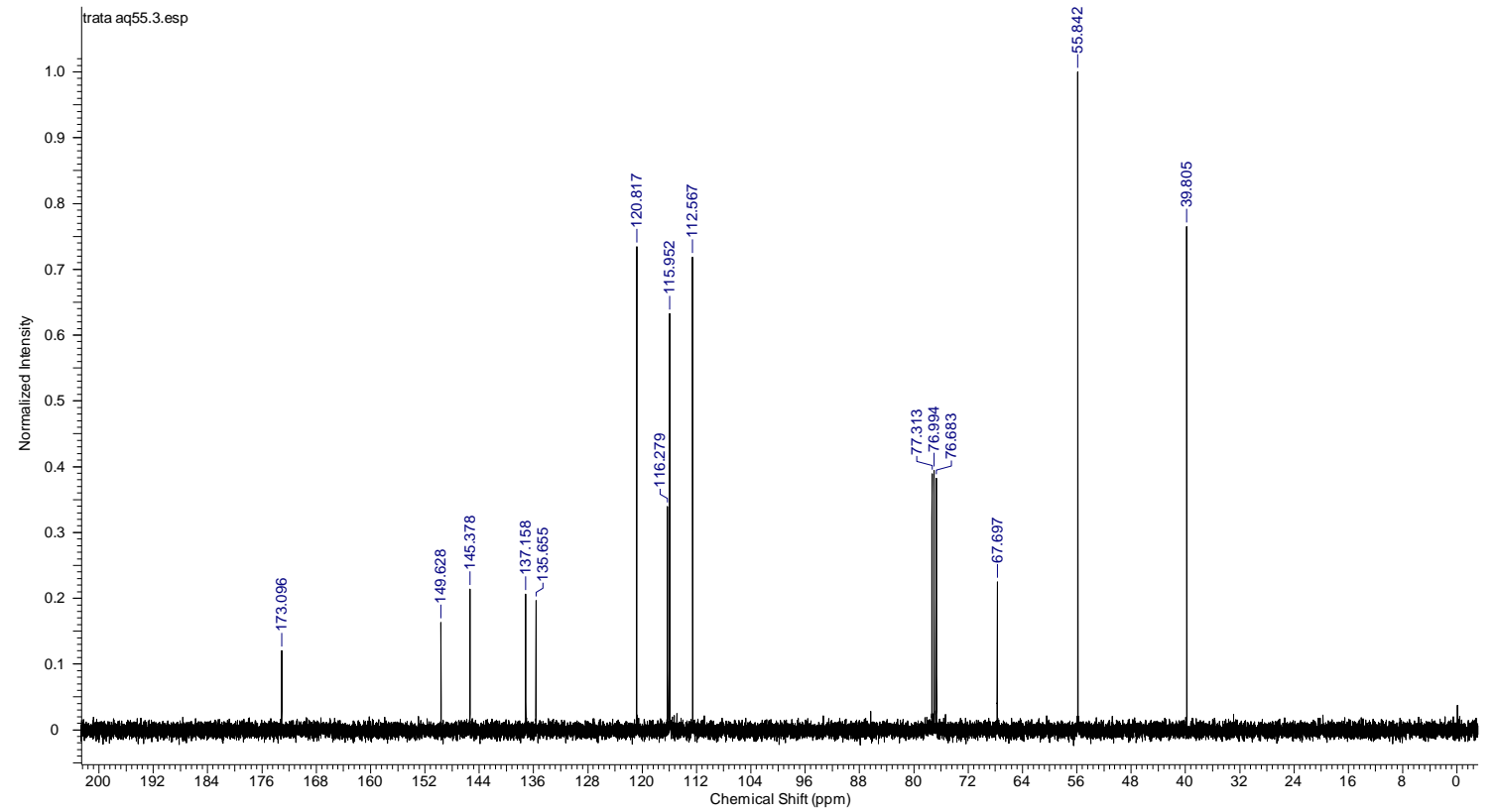

Figura 8S: Espectro de $\mathrm{RMN}^{13} \mathrm{C}\left(100 \mathrm{MHz}, \mathrm{CDCl}_{3}\right)$ do composto 5. 


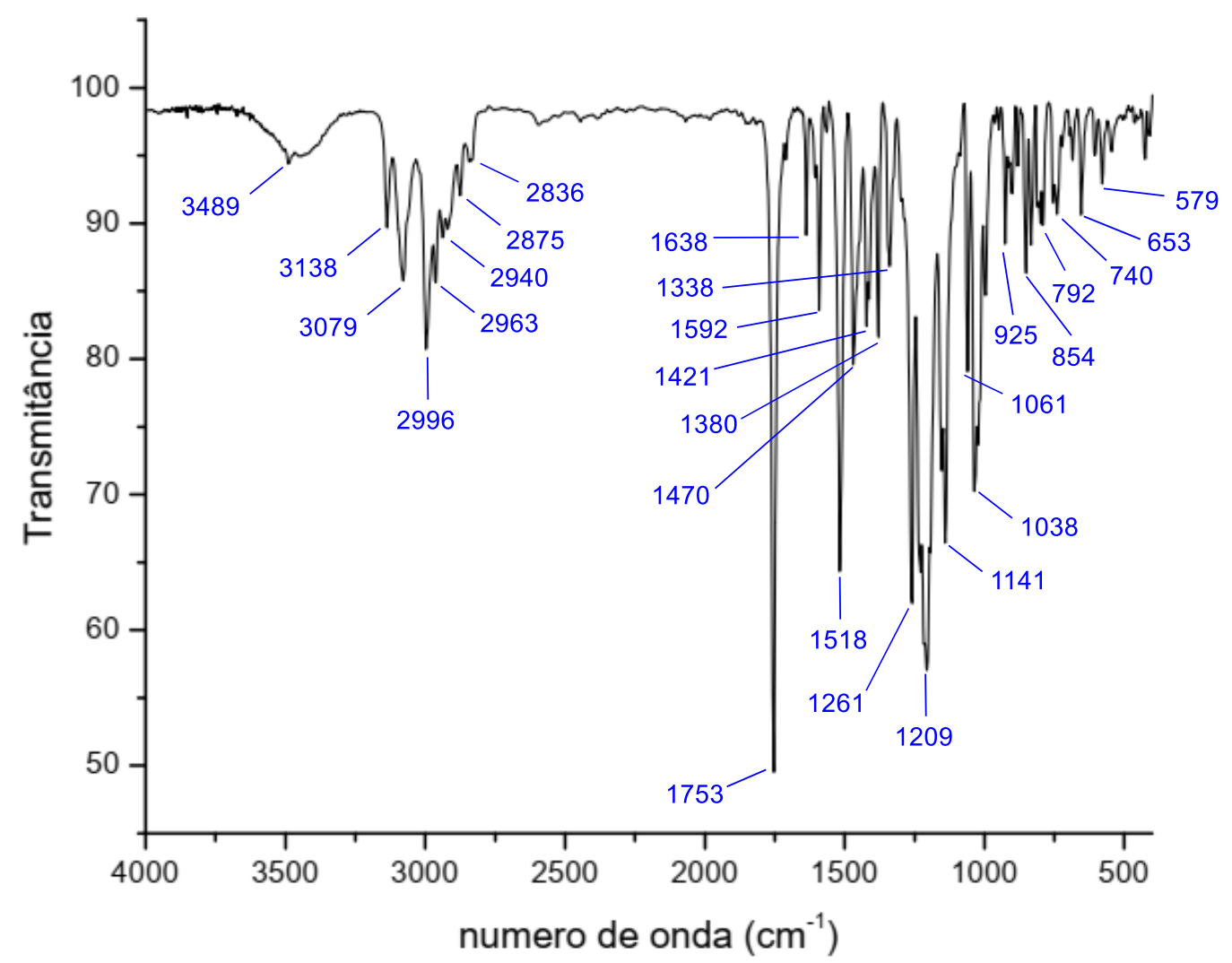

Figura 9S: Espectro de infravermelho em $\mathrm{KBr}$ do composto 6.

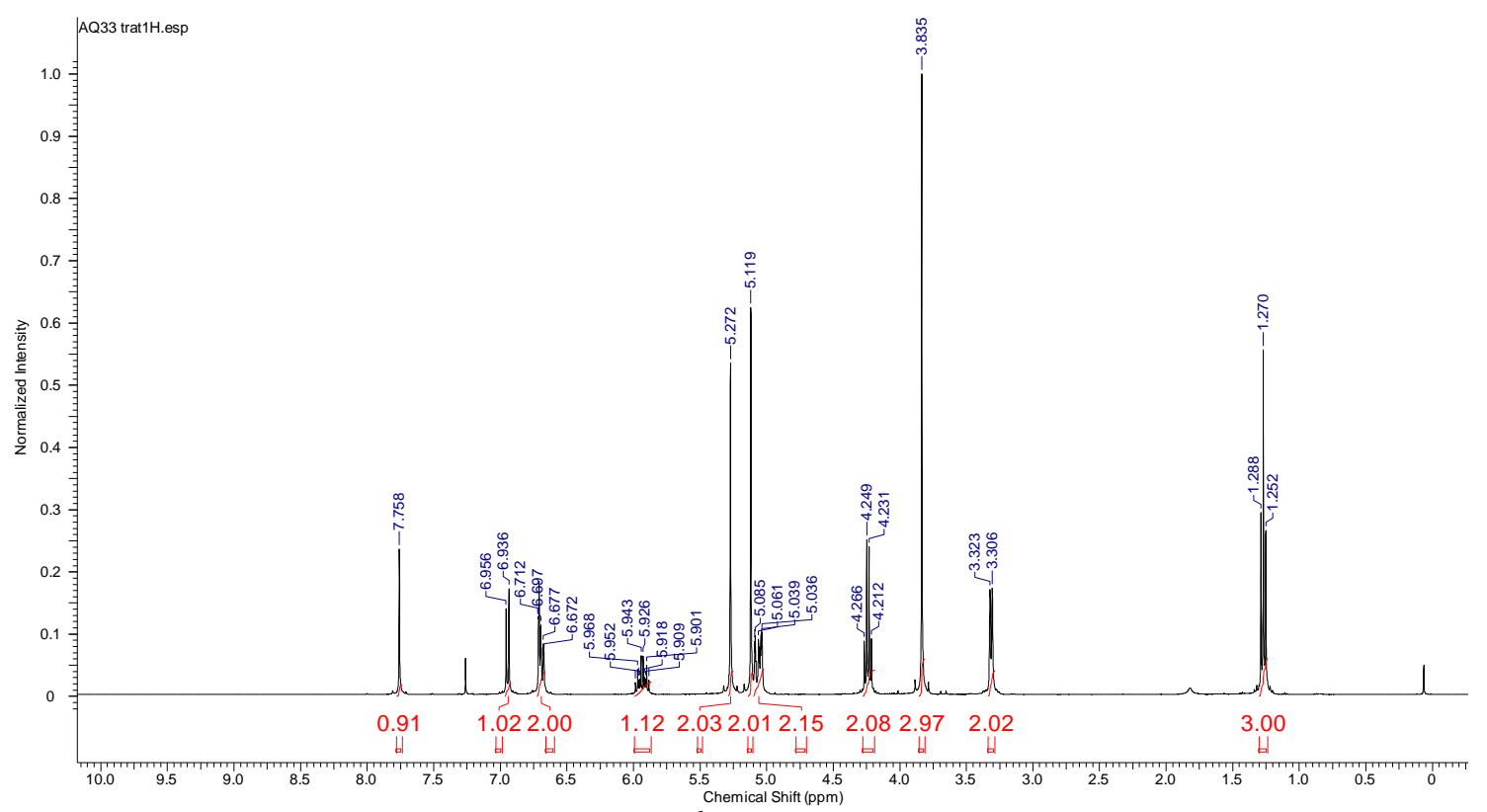

Figura 10S: Espectro de $R M N^{1} \mathrm{H}\left(400 \mathrm{MHz}, \mathrm{CDCl}_{3}\right)$ do composto 6. 


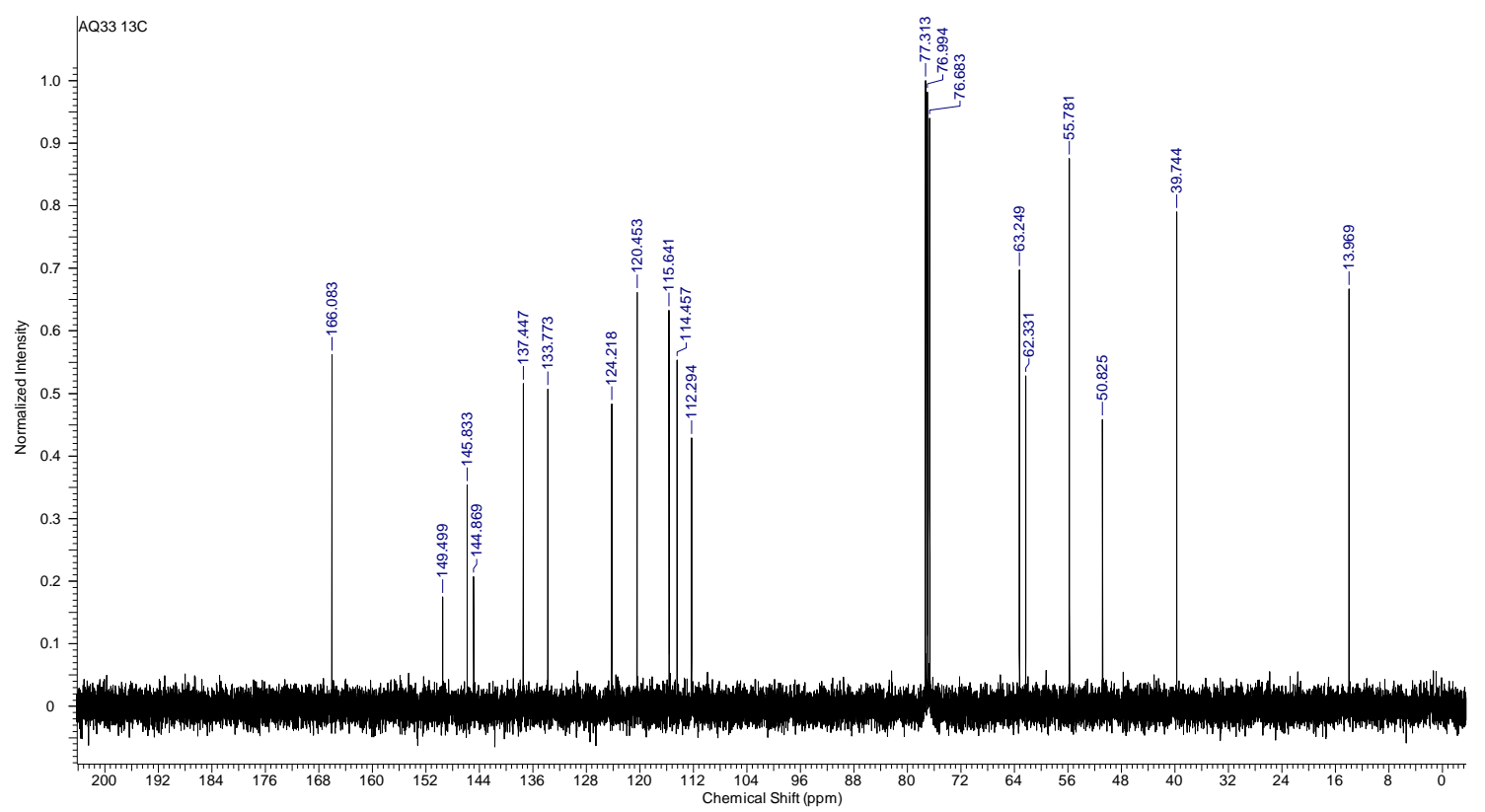

Figura 11S: Espectro de $\mathrm{RMN}^{13} \mathrm{C}\left(100 \mathrm{MHz}, \mathrm{CDCl}_{3}\right)$ do composto 6.

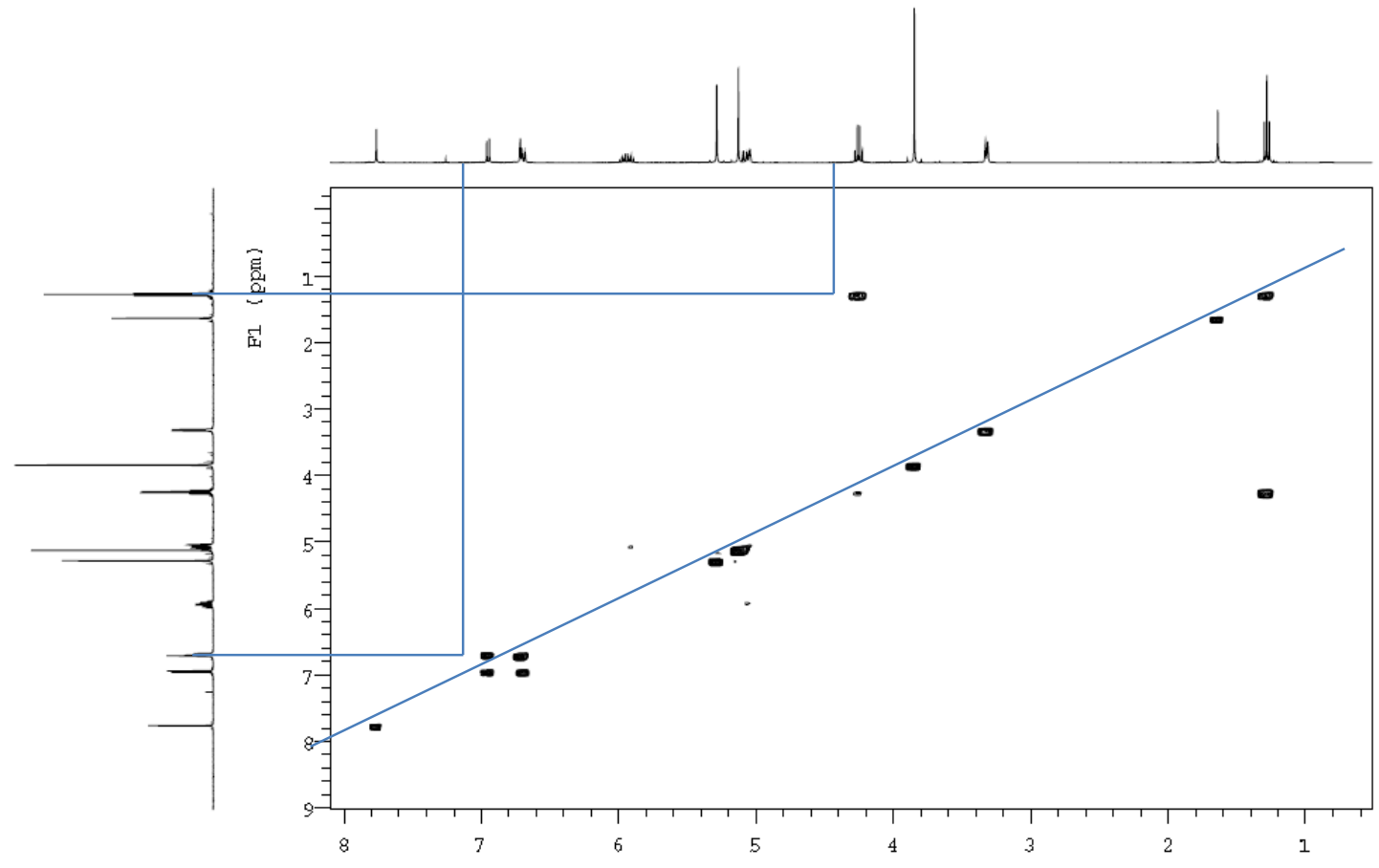

Figura 12S: Espectro de $\operatorname{COSY}\left(\mathrm{CDCl}_{3}\right)$ do composto 6. 


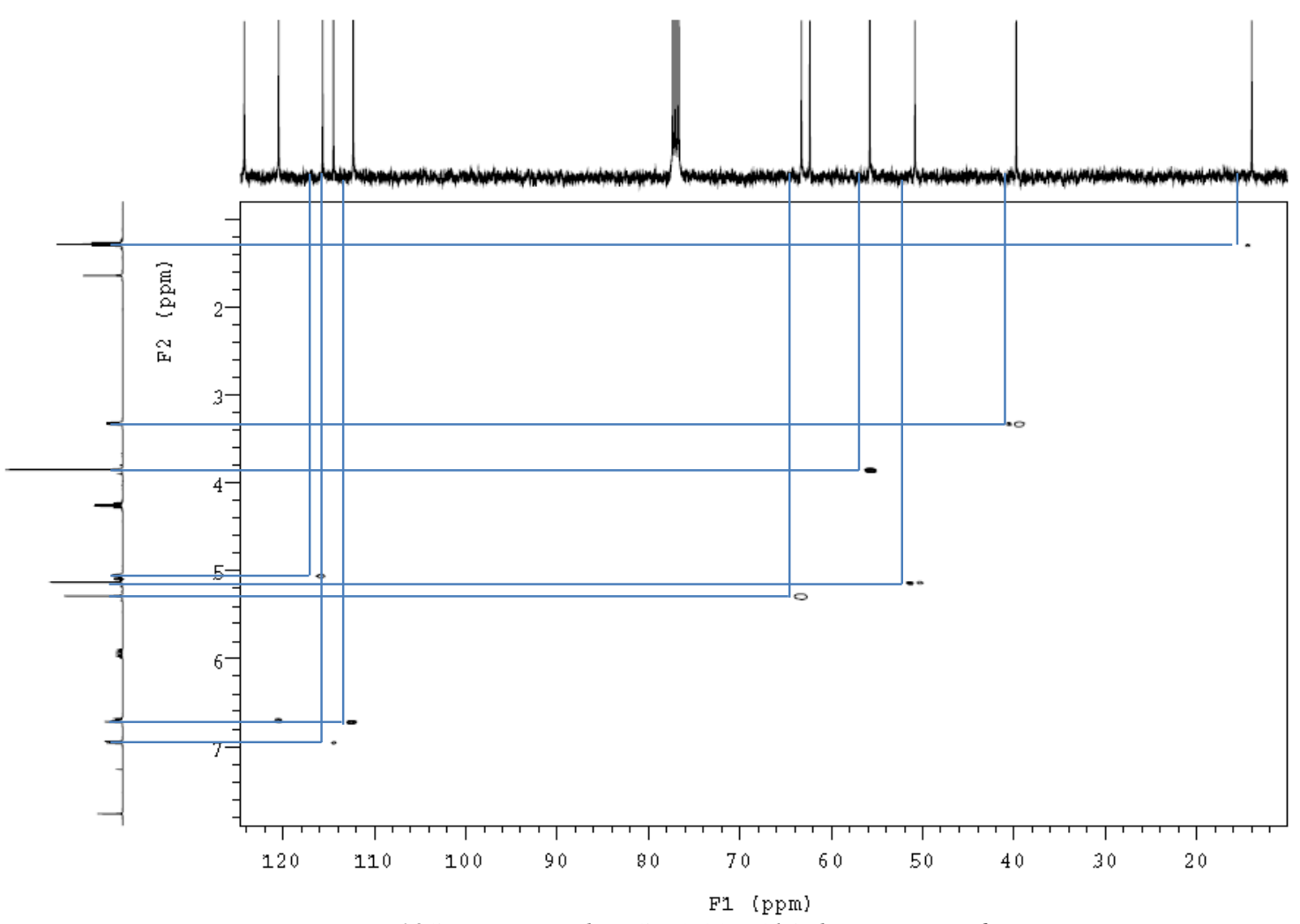

Figura 13S: Espectro de HSQC $\left(\mathrm{CDCl}_{3}\right)$ do composto 6.

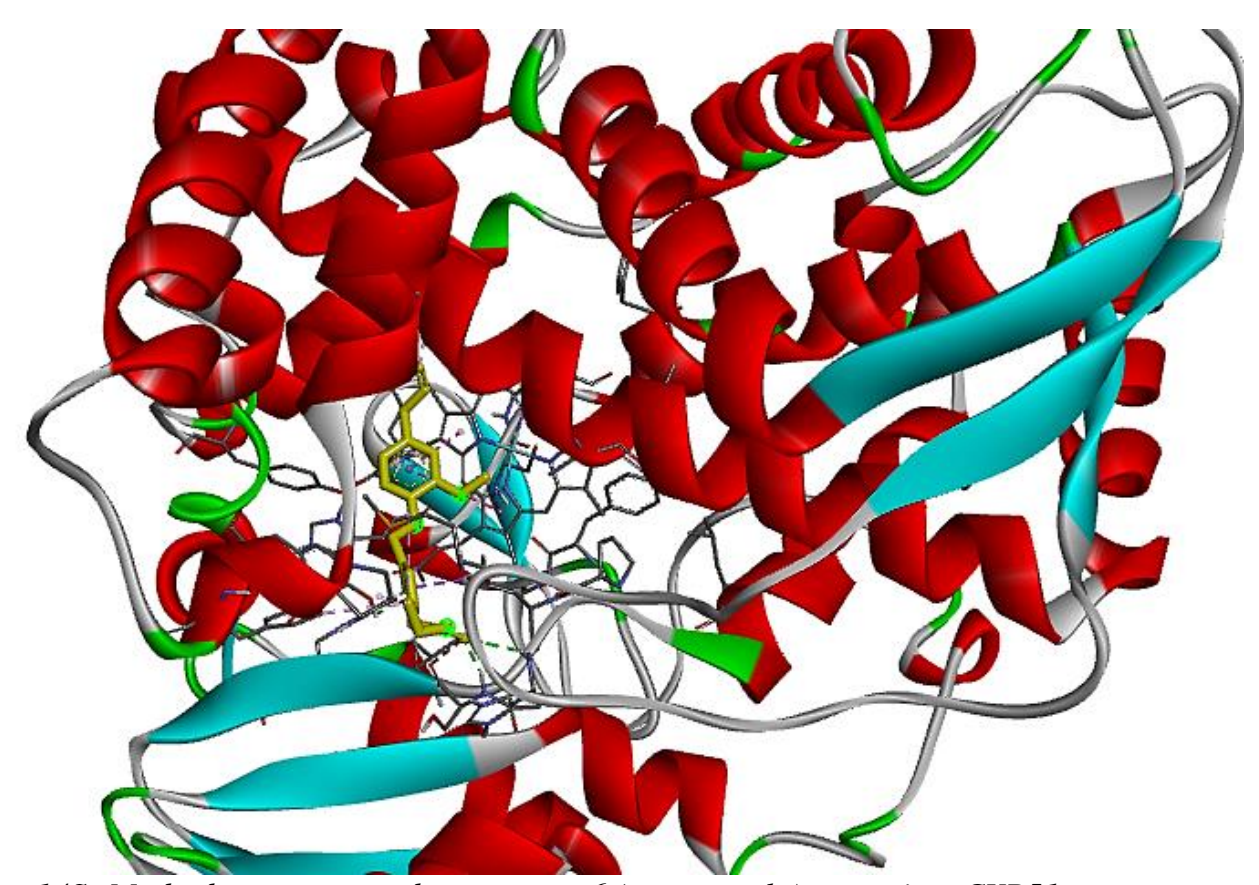

Figura 14S: Modo de ancoragem do composto 6 (em amarelo) na enzima CYP51. 


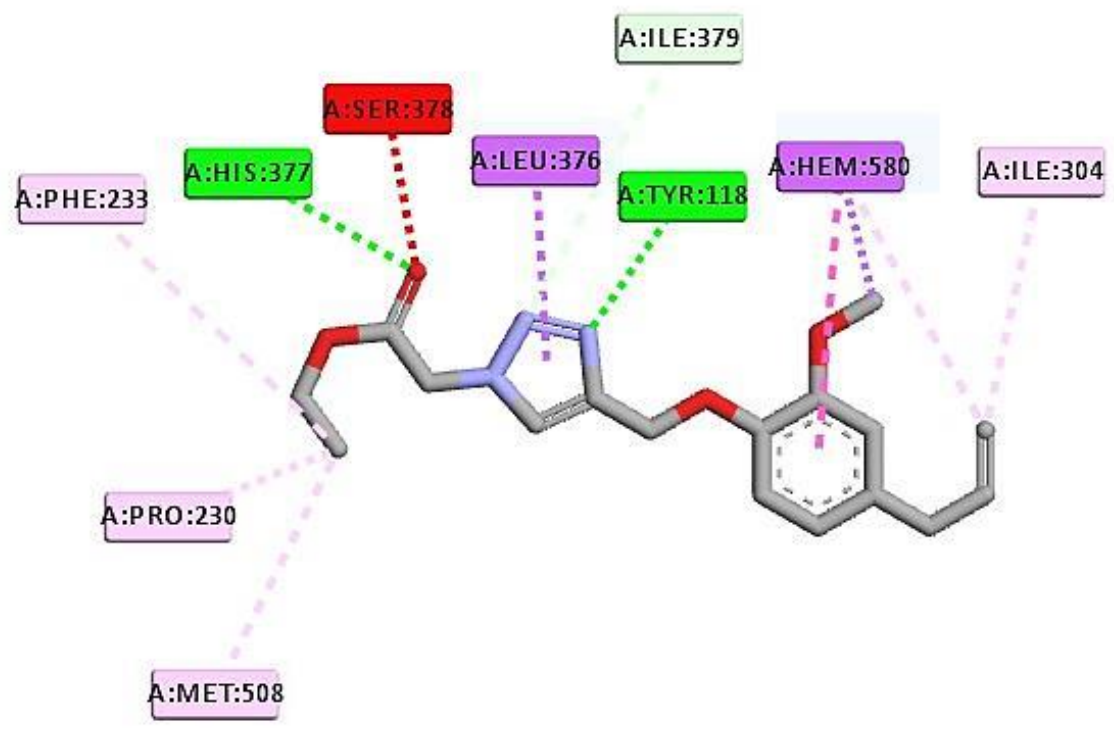

Interações

$\square$ Ligação de Hidrogênio Convencional $\square$ Pi-Pi Empilhado
$\square$ Ligação Hidrogênio Carbono $\quad \square$ Alquil
Aceptor-Aceptor Desfavorável $\square$ Pi-Alquil
Pi-Sigma

Figura 15S: Representação 2D das interações intermoleculares entre o composto 6 e a enzima CYP51.

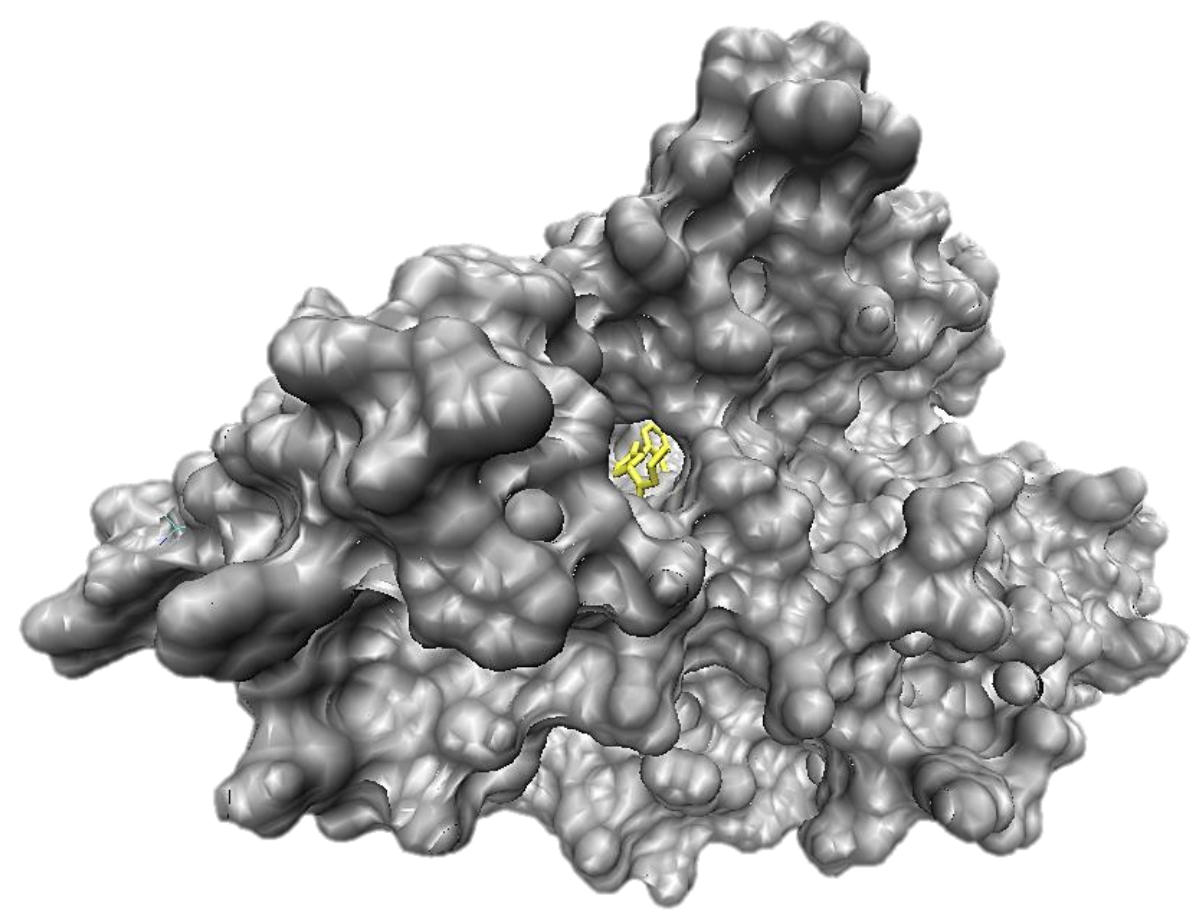

Figura 16S: Ancoragem do composto 6 (em amarelo) no sítio ativo da enzima CYP51. 


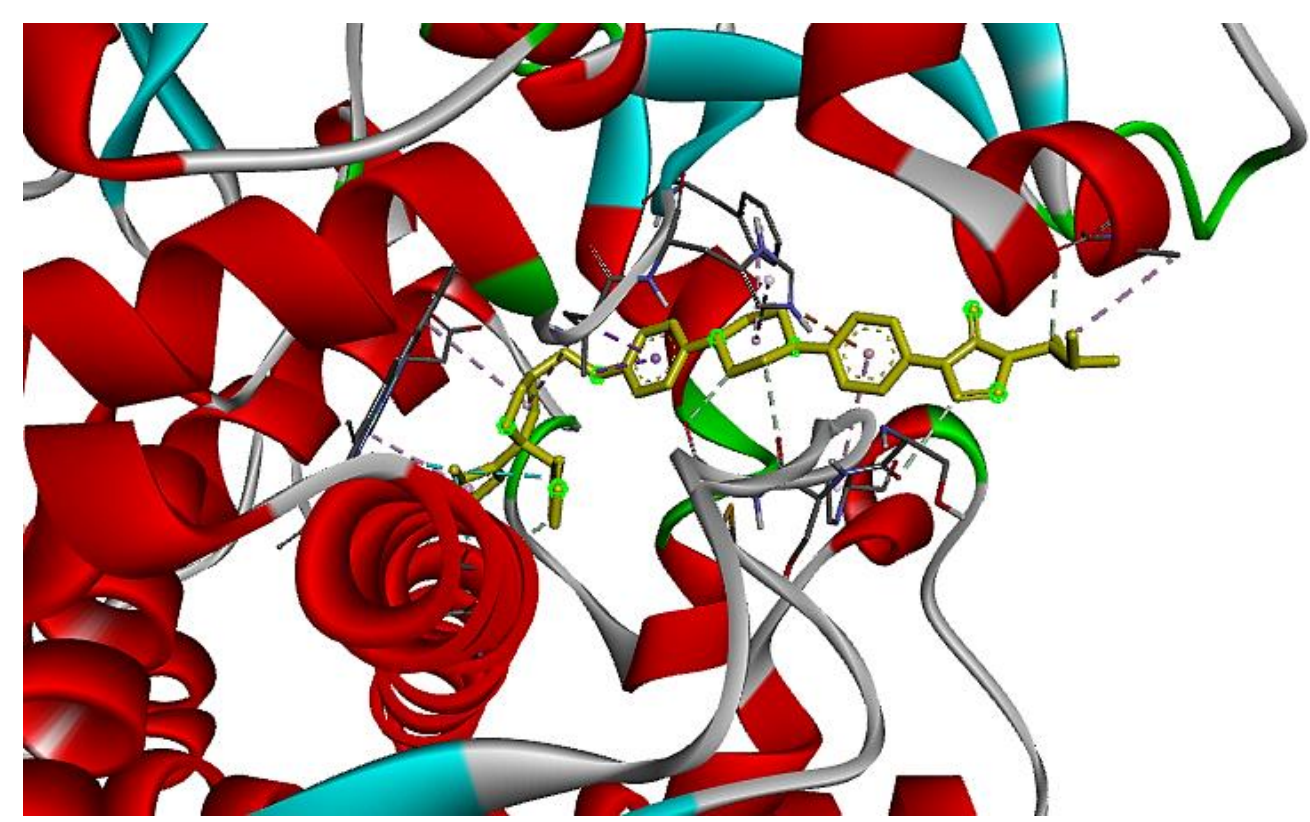

Figura 17S: Modo de ancoragem do posaconazol (em amarelo) na enzima CYP51.

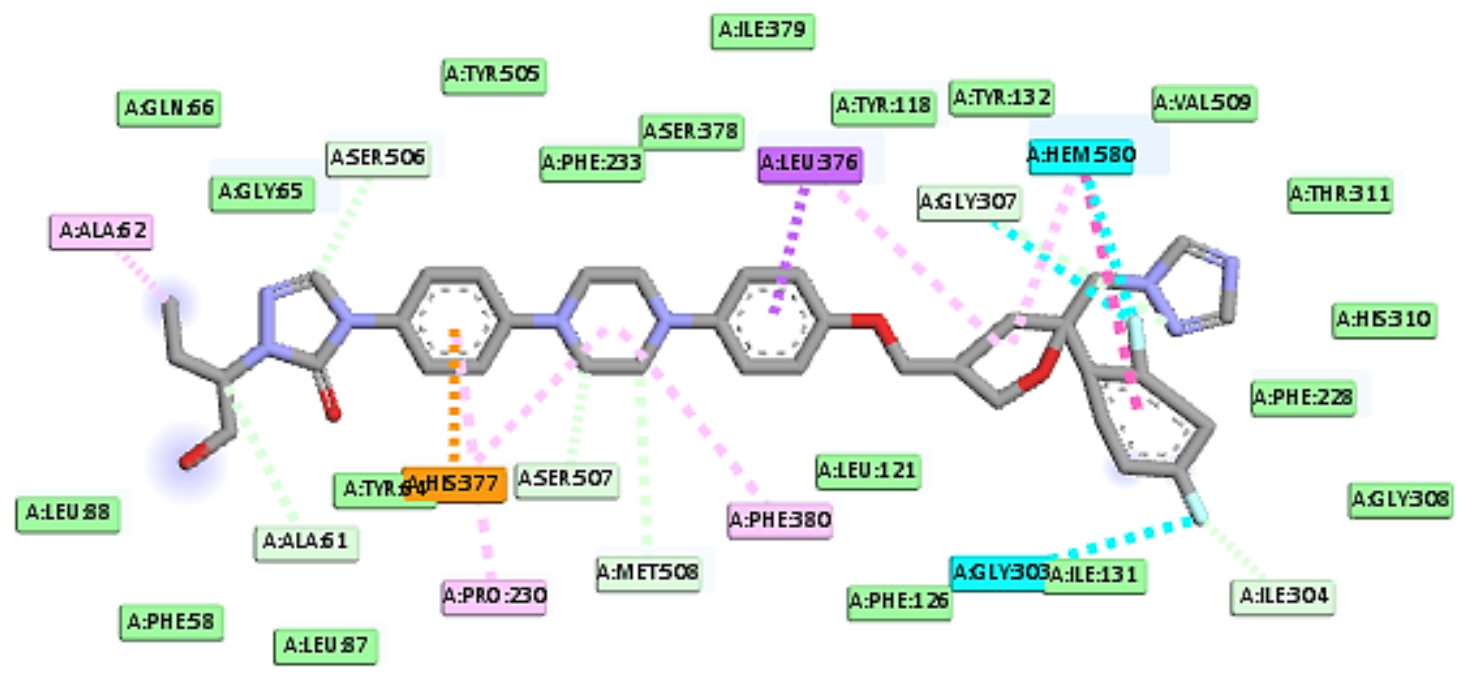

Interações

\begin{tabular}{ll}
$\square$ van der Waals & $\square$ Pi-Sigma \\
\hline Ligaçäo Hidrogênio Carbono & $\square$ Pi-Pi Empilhado \\
$\square$ Halogênio (Flúor) & $\square$ Alquil \\
\hline$\quad$ Pi-Cátion & $\square$ Pi-Alquil
\end{tabular}

Figura 18S: Representação 2D das interações intermoleculares entre o posaconazol e a enzima CYP51. 


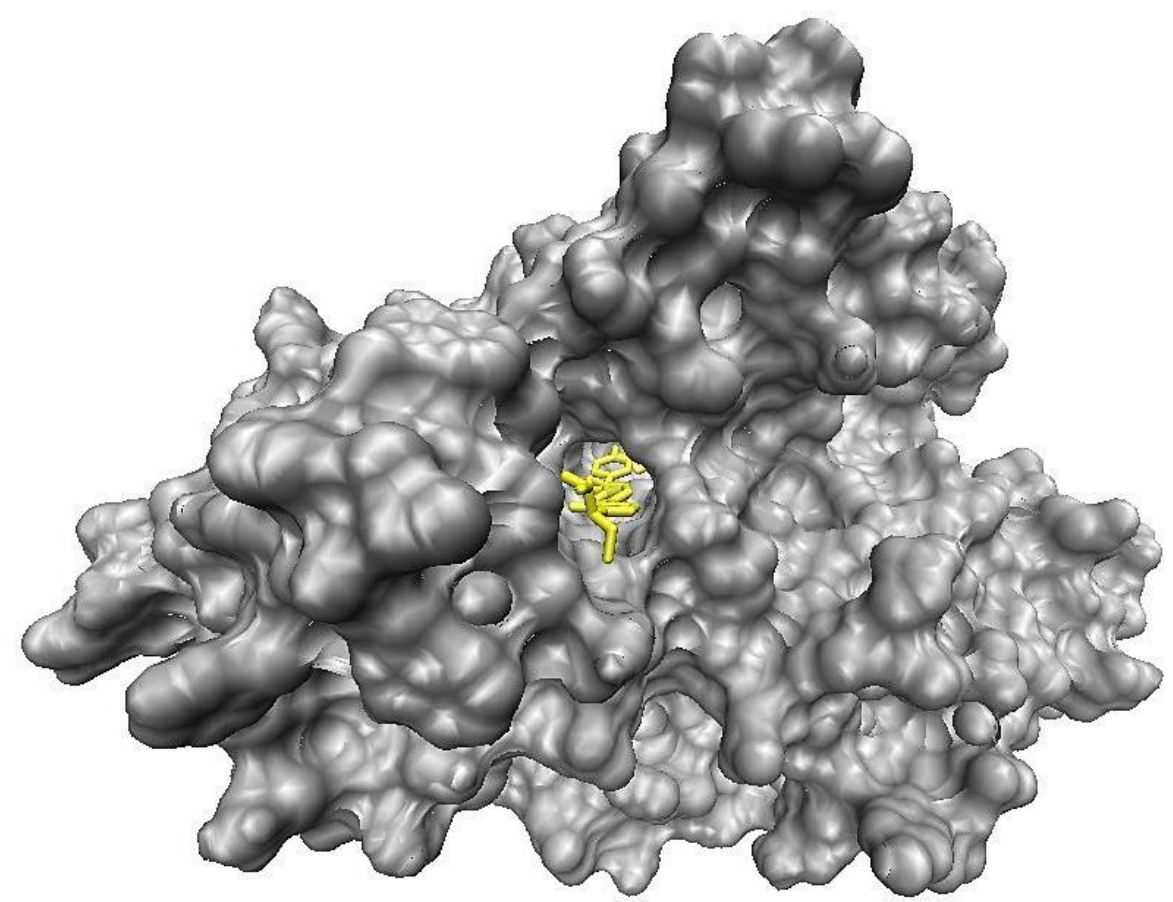

Figura 19S: Ancoragem do posaconazol (em amarelo) no sítio ativo da enzima CYP51. 